\title{
Aqueous phase oxidation of sulphur dioxide by ozone in cloud droplets
}

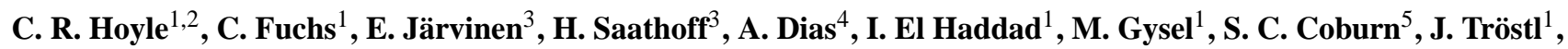
A.-K. Bernhammer ${ }^{6,16}$, F. Bianchi ${ }^{1}$, M. Breitenlechner ${ }^{6}$, J. C. Corbin ${ }^{1}$, J. Craven $^{7, a}$, N. M. Donahue ${ }^{8}$, J. Duplissy ${ }^{9}$, S. Ehrhart ${ }^{4}$, C. Frege ${ }^{1}$, H. Gordon ${ }^{4}$, N. Höppel ${ }^{3}$, M. Heinritzi ${ }^{10}$, T. B. Kristensen ${ }^{11}$, U. Molteni ${ }^{1}$, L. Nichman ${ }^{12}$, T. Pinterich ${ }^{13}$, A. S. H. Prévôt ${ }^{1}$, M. Simon ${ }^{10}$, J. G. Slowik ${ }^{1}$, G. Steiner ${ }^{9,6,13}$, A. Tomé ${ }^{14}$, A. L. Vogel ${ }^{4}$, R. Volkamer $^{5}$, A. C. Wagner ${ }^{10}$, R. Wagner ${ }^{9}$, A. S. Wexler ${ }^{15}$, C. Williamson ${ }^{10, b, c}$, P. M. Winkler ${ }^{13}$, C. Yan $^{9}$, A. Amorim ${ }^{14}$, J. Dommen ${ }^{1}$, J. Curtius ${ }^{10}$, M. W. Gallagher ${ }^{12,18}$, R. C. Flagan $^{7}$, A. Hansel ${ }^{6,16}$, J. Kirkby ${ }^{4,10}$, M. Kulmala ${ }^{9}$, O. Möhler ${ }^{3}$, F. Stratmann ${ }^{11}$, D. R. Worsnop ${ }^{9,17}$, and U. Baltensperger ${ }^{1}$

${ }^{1}$ Laboratory of Atmospheric Chemistry, Paul Scherrer Institute, Villigen, Switzerland

${ }^{2}$ WSL Institute for Snow and Avalanche Research SLF Davos, Switzerland

${ }^{3}$ Karlsruhe Institute of Technology, Institute for Meteorology and Climate Research, P.O. Box 3640,

76021 Karlsruhe, Germany

${ }^{4}$ CERN, 1211 Geneva, Switzerland

${ }^{5}$ Department of Chemistry and Biochemistry \& CIRES, University of Colorado, Boulder, CO, USA

${ }^{6}$ University of Innsbruck, Institute for Ion Physics and Applied Physics, Technikerstrasse 25, 6020 Innsbruck, Austria

${ }^{7}$ California Institute of Technology, Department of Chemical Engineering, Pasadena, CA 91125, USA

${ }^{8}$ Carnegie Mellon University Center for Atmospheric Particle Studies, 5000 Forbes Ave, Pittsburgh, PA 15213, USA

${ }^{9}$ Division of Atmospheric Sciences, Department of Physics, P.O. Box 64, 00014, University of Helsinki, Helsinki, Finland

${ }^{10}$ Goethe University of Frankfurt, Institute for Atmospheric and Environmental Sciences, 60438 Frankfurt am Main, Germany

${ }^{11}$ Leibniz Institute for Tropospheric Research, Permoserstrasse 15, 04318 Leipzig, Germany

${ }^{12}$ School of Earth, Atmospheric and Environmental Sciences, University of Manchester, Manchester, M13 9PL, UK

${ }^{13}$ University of Vienna, Faculty of Physics, Aerosol and Environmental Physics, Boltzmanngasse 5, 1090 Vienna, Austria

${ }^{14}$ CENTRA-SIM, University of Lisbon and University of Beira Interior, 1749-016 Lisbon, Portugal

${ }^{15}$ Departments of Mechanical and Aeronautical Engineering, Civil and Environmental Engineering, and Land, Air, and Water

Resources, University of California, Davis, CA, USA

${ }^{16}$ Ionicon Analytik GmbH, Eduard-Bodem-Gasse 3, 6020 Innsbruck, Austria

${ }^{17}$ Aerodyne Research Inc., Billerica, MA 01821, USA

${ }^{18}$ NERC Instrument PI, National Centre for Atmospheric Science (NCAS), Leeds, UK

${ }^{a}$ now at: Portland Technology Development Division of Intel, Hillsboro, OR, USA

${ }^{b}$ now at: Chemical Sciences Division NOAA Earth System Research Laboratory 325 Broadway R/CSD2 Boulder, CO, USA

${ }^{c}$ now at: Cooperative Institute for Research in Environmental Sciences, University of Colorado Boulder, Boulder, CO, USA

Correspondence to: C. R. Hoyle (christopher.hoyle@psi.ch)

Received: 30 October 2015 - Published in Atmos. Chem. Phys. Discuss.: 1 December 2015

Revised: 28 January 2016 - Accepted: 29 January 2016 - Published: 12 February 2016 
Abstract. The growth of aerosol due to the aqueous phase oxidation of sulfur dioxide by ozone was measured in laboratory-generated clouds created in the Cosmics Leaving OUtdoor Droplets (CLOUD) chamber at the European Organization for Nuclear Research (CERN). Experiments were performed at 10 and $-10^{\circ} \mathrm{C}$, on acidic (sulfuric acid) and on partially to fully neutralised (ammonium sulfate) seed aerosol. Clouds were generated by performing an adiabatic expansion - pressurising the chamber to $220 \mathrm{hPa}$ above atmospheric pressure, and then rapidly releasing the excess pressure, resulting in a cooling, condensation of water on the aerosol and a cloud lifetime of approximately $6 \mathrm{~min}$. A model was developed to compare the observed aerosol growth with that predicted using oxidation rate constants previously measured in bulk solutions. The model captured the measured aerosol growth very well for experiments performed at 10 and $-10^{\circ} \mathrm{C}$, indicating that, in contrast to some previous studies, the oxidation rates of $\mathrm{SO}_{2}$ in a dispersed aqueous system can be well represented by using accepted rate constants, based on bulk measurements. To the best of our knowledge, these are the first laboratory-based measurements of aqueous phase oxidation in a dispersed, supercooled population of droplets. The measurements are therefore important in confirming that the extrapolation of currently accepted reaction rate constants to temperatures below $0{ }^{\circ} \mathrm{C}$ is correct.

\section{Introduction}

Sulphur dioxide is an important tropospheric species, influencing air quality as well as the acidity of precipitation (and therefore that of soil, lakes and rivers). It also influences climate directly and indirectly through its oxidation to sulphate and subsequent role in atmospheric new particle formation (e.g. Kulmala, 2003; Riccobono et al., 2014), and the growth of aerosol particles (e.g. Hoppel et al., 1994a) and thus its effect on their cloud condensation nuclei $(\mathrm{CCN})$ properties (e.g. Hobbs, 1971).

Global anthropogenic emissions of $\mathrm{SO}_{2}$ around the year 1990 were estimated to be approximately $73 \mathrm{TgS} \mathrm{yr}^{-1}$ (Rodhe, 1999), more than twice the total sulphur emissions from natural sources. Similar values were given by Faloona (2009) in a review of modelled $\mathrm{SO}_{2}$ emissions. In heavily industrialised regions, the ratio of anthropogenic to natural emissions can be higher than 10 . Although air quality legislation in Europe and the USA has led to a significant decline in industrial emissions of $\mathrm{SO}_{2}$ in the last couple of decades, emissions from Asia and developing countries in other locations are increasing (Forster et al., 2007).

The major sink of atmospheric $\mathrm{SO}_{2}$ is oxidation to sulphate, estimated at approximately $51 \mathrm{Tg} \mathrm{S} \mathrm{yr}^{-1}$ (Faloona, 2009), and anthropogenic emissions of $\mathrm{SO}_{2}$ account for approximately $72 \%$ of sulphate aerosol in the atmosphere (Forster et al., 2007).
$\mathrm{SO}_{2}$ is either oxidised in the gas phase (by reaction with the $\mathrm{OH}$ radical), or it can be taken up by cloud droplets and undergo aqueous phase oxidation. In the aqueous phase, oxidation is primarily by reaction with $\mathrm{H}_{2} \mathrm{O}_{2}$ or $\mathrm{O}_{3}$, with the $\mathrm{O}_{3}$ reaction becoming larger than typical gas phase reaction rates at $\mathrm{pH}$ higher than approximately 4 (Seinfeld and Pandis, 2006). Model studies suggest that aqueous oxidation comprises a large majority of the global sulphate production, perhaps $80 \%$ or more (Faloona, 2009; Barth et al., 2000), however the range of model estimates is rather large, reflecting the difficulty in reproducing cloud processes in large-scale models.

The aqueous phase oxidation of $\mathrm{SO}_{2}$ by $\mathrm{O}_{3}$ proceeds by the absorption of $\mathrm{SO}_{2}$ into the cloud droplet, and the establishment of equilibrium between $\mathrm{SO}_{2} \cdot \mathrm{H}_{2} \mathrm{O}, \mathrm{HSO}_{3}^{-}$, and $\mathrm{SO}_{3}^{2-}$. Dissolved $\mathrm{O}_{3}$ then oxidises the latter three species, forming $\mathrm{SO}_{4}^{2-}$. The Henry's law coefficients for dissolution of $\mathrm{O}_{3}$ and $\mathrm{SO}_{2}$, as well as the equilibrium constants for the hydration of $\mathrm{SO}_{2}$ and the reaction rate constants for the subsequent reaction with $\mathrm{O}_{3}$ have all been well studied in bulk solutions in the past (predominantly at temperatures of approximately $20^{\circ} \mathrm{C}$ or higher, see Sect. 3.2). The oxidation rate constants recommended by Hoffmann (1986) are commonly adopted in models simulating cloud chemistry (for example, all of the seven models simulating $\mathrm{SO}_{2}$ oxidation in clouds, which were compared by Kreidenweis et al., 2003, used these rate constants). However, to the best of our knowledge, no studies have been performed at temperatures below $0^{\circ} \mathrm{C}$, thus values for sub-zero temperatures are based on extrapolations of the temperature dependence at higher temperatures. The temperature dependence recommended by Hoffmann (1986), and adopted in most modelling studies, is that of Erickson et al. (1977), based on measurements at 25 and $16^{\circ} \mathrm{C}$. In that study, experiments were only performed up to a pH of 4.02, where the vast majority (i.e. 0.994) of dissolved $\mathrm{S}(\mathrm{IV})$ is present as $\mathrm{HSO}_{3}^{-}$. At higher $\mathrm{pH}$, as encountered in cloud droplets, more of the $\mathrm{S}(\mathrm{IV})$ is present as $\mathrm{SO}_{3}^{2-}$, for which the rate constant for reaction with $\mathrm{O}_{3}$ is approximately 4 orders of magnitude higher than that for $\mathrm{HSO}_{3}^{-}$. The temperature dependence of this reaction is therefore very important. Measurements performed by Maahs (1983), at 25 and $10^{\circ} \mathrm{C}$, using buffered solutions at $\mathrm{pH}$ up to $6.2 \mathrm{sug}$ gest a slightly weaker temperature dependence, and therefore greater oxidation rates at low temperatures than suggested by Erickson et al. (1977).

A few previous cloud chamber studies have examined the aqueous phase oxidation of $\mathrm{SO}_{2}$ in cloud droplets, hydrated aerosol, and fogs, with the aim of reconciling reaction rate constants measured in bulk solutions with those inferred from $\mathrm{S}(\mathrm{VI})$ production in a dispersed aqueous system. As discussed below, the results are mixed, and it is not possible to exclude the influence of un-measured contaminants on the rate of S(IV) oxidation. 
The $6.7 \mathrm{~m}^{3}$, Desert Research Institute Dynamic Cloud Chamber was described by Steele et al. (1981), who performed experiments with the oxidation of $\mathrm{SO}_{2}$ in droplets formed on a range of $\mathrm{CCN}$, without the addition of extra oxidants such as $\mathrm{O}_{3}$. The same chamber was then used by Miller et al. (1986) to perform experiments with the addition of $\mathrm{O}_{3}$. They used a $\mathrm{Na}_{2} \mathrm{SO}_{4}$ seed aerosol, and formed clouds by performing adiabatic expansions, which produced temperature decreases from approximately 21 to $10^{\circ} \mathrm{C}$, and cloud lifetimes of 440 to $490 \mathrm{~s}$. Although the chamber could maintain a minimum wall temperature of $-40^{\circ} \mathrm{C}$, they only performed experiments beginning around $20^{\circ} \mathrm{C}$, representative of warm clouds. Similarly to the present study, they used $\mathrm{O}_{3}$ mixing ratios of 120 to $150 \mathrm{ppbv}$, with a wider range of $\mathrm{SO}_{2}$ mixing ratios (23 to $310 \mathrm{ppbv}$ ). They found good agreement between the measured (dual channel ion chromatograph) increase in $\mathrm{S}(\mathrm{VI})$ in the cloud water, and values calculated using the oxidation rate constants measured by Erickson et al. (1977) in bulk solutions, suggesting that such rate constants are indeed applicable to the chemistry occurring in cloud droplets, at warm temperatures.

The aqueous phase oxidation of $\mathrm{SO}_{2}$ by $\mathrm{H}_{2} \mathrm{O}_{2}$ and by $\mathrm{O}_{3}$ was also investigated in the Calspan $590 \mathrm{~m}^{3}$ environmental chamber by Hoppel et al. (1994b). The chamber was filled with outside air that had been filtered through activated charcoal and aerosol filters and experiments were performed at ambient temperature. After humidifying the air and injecting $\mathrm{O}_{3}$ and $\mathrm{SO}_{2}$, they achieved 4 min cloud periods by performing adiabatic expansions from $15 \mathrm{mb}$ over atmospheric pressure to $5 \mathrm{mb}$ below atmospheric pressure. Aqueous phase oxidation rates determined from the resulting aerosol growth were found to be much faster than those inferred using the bulk measurement based rate constants recommended by Hoffmann (1986). This experiment was repeated by Caffrey et al. (2001), with improved instrumentation and an improved model, but the measured oxidation rates were still found to be a factor of 5 higher than those of Hoffmann (1986). Small amounts of un-measured ammonia contamination (increasing the droplet $\mathrm{pH}$ and raising the reaction rate) were given as a possible explanation.

The CLOUD (Cosmics Leaving Outdoor Droplets) chamber at CERN provides an essentially contaminant free, and precisely controlled environment in which to perform experimental observations of aqueous phase reactions occurring in cloud droplets. In this study, the aqueous phase oxidation rate of $\mathrm{SO}_{2}$ by $\mathrm{O}_{3}$, in cloud droplets is examined. This study is based on measurements performed during two experimental campaigns, in 2013 (CLOUD8) and 2014 (CLOUD9). Experiments were carried out at temperatures of 10 and $-10^{\circ} \mathrm{C}$, with acidic $\left(\mathrm{H}_{2} \mathrm{SO}_{4}\right)$ and partially to fully neutral (ammonium sulphate) aerosol as $\mathrm{CCN}$, and a chemicalmicrophysical model of the chamber was written to compare commonly accepted reaction rates with the formation of sulphate observed in the cloud chamber droplets.
In the next section, the CLOUD chamber and associated instrumentation is described. In Sect. 3, the details of the model are given, and in Sect. 4 we present a discussion of the results of the experiments and a comparison with the modelled values. Conclusions are drawn in Sect. 5.

\section{Experimental setup}

The experiments were conducted in the CLOUD chamber at CERN. The chamber consists of a $3 \mathrm{~m}$ diameter electropolished stainless steel cylinder, with a volume of $26.1 \mathrm{~m}^{3}$. The temperature in the chamber can be accurately controlled at any point between 183 and $300 \mathrm{~K}$, by regulating the temperature of air flowing between the chamber wall and its thermal insulation housing (Kirkby et al., 2011). Experiments are performed in a well-mixed flow chamber mode, with the sample air drawn off by the instruments continually being replaced, and the mixing ratio of any added gas phase species being held approximately constant. In CLOUD8, the sample flow, and therefore the addition of gases to the chamber totalled $250 \mathrm{~L} \mathrm{~min}^{-1}$, leading to a dilution lifetime of $105 \mathrm{~min}$. In CLOUD9, the sample flow demands of the instruments were lower, leading to a flow of $150 \mathrm{~L} \mathrm{~min}^{-1}$ and thus a dilution lifetime of $174 \mathrm{~min}$. As species such as $\mathrm{O}_{3}$ and $\mathrm{SO}_{2}$ were continually added to the chamber to maintain approximately constant mixing ratios, the dilution lifetime only applies to the concentration of the aerosol particles.

Gases in the chamber were mixed by two stainless steel fans, mounted at the top and bottom of the chamber, and magnetically coupled to their gearboxes, which are mounted outside the chamber. Between CLOUD8 and CLOUD9, the gearboxes were upgraded to allow a fourfold increase in fan speed, but, for the experiments presented here, the fans were set to the same speed in CLOUD8 and CLOUD9. At the beginning of a series of experiments, the chamber is cleaned by heating to $373 \mathrm{~K}$, flushing with ultra-pure water, and drying with a pure air flow, resulting in extremely low levels of contaminants. The pure air added to the chamber is created by the evaporation of liquid $\mathrm{N}_{2}$ and liquid $\mathrm{O}_{2}$, at a ratio of $79: 21$. The desired relative humidity $(\mathrm{RH})$ in the chamber is achieved by passing the necessary fraction of the inflow air through a Nafion humidifier, using water which was purified by recirculation through a bank of Millipore Super-Q filters and irradiated with ultraviolet radiation to suppress biological activity (this treatment process is also used to create the water used to clean the chamber). $\mathrm{SO}_{2}$ is added to the chamber from a gas cylinder ( $998.2 \mathrm{ppmv} \pm 2 \%$ in $\mathrm{N}_{2}$ ), as is $\mathrm{NH}_{3}$ for the neutral seed experiments $\left(1 \% \mathrm{NH}_{3}\right.$ in $\left.\mathrm{N}_{2}\right) . \mathrm{O}_{3}$ is created by irradiating a pure air flow at wavelengths below $200 \mathrm{~nm}$, in an external $\mathrm{O}_{3}$ generator, from which it is piped into the chamber. All gases have dedicated lines for injection into the chamber to avoid contamination and reactions occurring in the gas lines. Fittings and gas lines are made 
from stainless steel to avoid contamination. More details of the CLOUD chamber are given in Duplissy et al. (2016).

\subsection{Expansion system}

By increasing the input flow of air beyond the sample flow drawn off by the instruments, the chamber can be pressurised up to $220 \mathrm{hPa}$ above ambient pressure. This overpressure can be released through an exhaust valve, resulting in an adiabatic cooling, and, at sufficiently high initial RH, the activation of aerosol particles to form cloud droplets. At lower temperatures, ice particles may form. The pressure-release valve is computer controlled, and can be programmed to follow a linear decrease in pressure over a given time period, or to follow any other prescribed pressure profile, such as an initial rapid pressure decrease until a cloud is formed, followed by a slower pressure reduction to maintain the cloud as long as possible. A vacuum pump is mounted in the exhaust line, to ensure that the rate of change of pressure does not decrease with the difference between the chamber and ambient pressure. During and after the adiabatic cooling, the air in the chamber is continually heated by the chamber walls, as the temperature control system is maintained at the preexpansion temperature, causing the evaporation of the cloud after approximately $4-6 \mathrm{~min}$.

\subsection{Temperature and pressure measurement}

The temperature inside the chamber was measured with a string of six thermocouples (TC, type $\mathrm{K}$ ) which were mounted horizontally between the chamber wall and the centre of the chamber at distances of 100, 170, 270, 400, 650, and $950 \mathrm{~mm}$ from the chamber wall. The line of thermocouples was located midway between the top and bottom of the chamber. The TC have a precision of below $0.1^{\circ} \mathrm{C}$, and were calibrated by an in situ measurement with a string of well calibrated Pt100 sensors (one at each TC position). The temperature measured before, during and after an expansion is shown in Fig. 1. During normal operation, there was no systematic horizontal gradient across the chamber. During expansions, a small oscillation in the temperature was observed. This is caused by the mixing of air within the chamber, with the variation between the temperature sensors being typically lower than approximately $0.5^{\circ} \mathrm{C}$. In the modelling work here, the temperature was taken as the mean of the 3 innermost TCs (TC4-TC6).

The pressure in the chamber was measured by a Vegabar 51 pressure transmitter with a precision of 0.1 bar.

\subsection{Trace gas and aerosol measurement configuration}

The gas phase concentrations of $\mathrm{SO}_{2}$ and $\mathrm{O}_{3}$ were measured by trace gas monitors (Enhanced Trace Level $\mathrm{SO}_{2}$ Analyser, Model 43i-TLE, Thermo Scientific and $\mathrm{O}_{3}$ Analyser, Thermo Environmental Instruments Inc., Model 49C, respectively). A proton transfer reaction time of flight mass spectrometer
(PTR-TOF-MS) with a mass resolving power of 4000-5000 $(m / \Delta m, \mathrm{FWHM})$ and a mass accuracy within $10 \mathrm{ppm}$ (Graus et al., 2010) was present, however the gas phase ammonia was typically below the detection limit during the experiments. The aerosol particle number size distributions were simultaneously measured by three different scanning mobility particle sizer (SMPS) systems, consisting of a differential mobility sizer (DMA) and a condensation particle counter (CPC, TSI model 3010). The first of these was attached to a total sampling line that allowed the measurement of all aerosols in the chamber. The second was attached to a cyclone, with a cut off of $2 \mu \mathrm{m}$, which enabled the measurement of the interstitial (i.e. non-activated) aerosol during the cloud periods. During the subsaturated periods the SMPS attached to the total and the interstitial lines measure essentially the same size distributions. The third SMPS was attached to an additional sampling line, on which a pumped counterflow virtual impactor (PCVI) was installed with the PCVI flow rate set for a cutoff of $5 \mu \mathrm{m}$, thus sampling only the aerosol contained in cloud droplets. The three SMPS systems scanned the size range between 17 and $415 \mathrm{~nm}$ approximately every minute. Unfortunately, the PCVI and cyclone appear to have been influenced by pressure changes during the expansions. It is, therefore, not possible to clearly identify the activated fraction of aerosol from these measurements.

The total humidity in the chamber was measured by MBW dew point mirror instruments (model MBW973 during CLOUD9 and MBW373LX during CLOUD8) attached to a heated sampling line. During CLOUD9 a tuneable diode laser (TDL) hygrometer, comparable to the APicT instrument as described by Fahey et al. (2014), was used to measure the water vapour content in situ with $1 \mathrm{~Hz}$ time resolution using a single optical path once across the middle plane of the CLOUD chamber. From the difference between total water and water vapour, the liquid water content (LWC) or ice water content (IWC) could be calculated. An optical particle sizer (WELAS Promo 2000, Palas GmbH) measured the droplet size distributions during the cloud periods. An in situ particle backscatter instrument (the SIMONE, Schnaiter et al., 2012) detected the presence of droplets and phase transitions within the chamber. In addition, the Particle Phase Discriminator mark 2, Karlsruhe edition (PPD-2K) was used to monitor the phase of particles in the size range of 6 to $60 \mu \mathrm{m}$, and thus to detect ice formation. Ice particles and water droplets were differentiated by the PPD-2K based on their forward scattering signals (Vochezer et al., 2016).

The droplet size distributions were also measured during the cloud periods with the cloud and aerosol spectrometer with polarisation detection (CASPOL), which measures the forward and backward scattering from single particles in the diameter range of 0.6 to $50 \mu \mathrm{m}$ (Glen and Brooks, 2013).

During both CLOUD8 and CLOUD9, the saturation relative humidity ( $100 \%$ with respect to liquid water) was determined from the chamber temperature at the time that the SIMONE first detected an increased forward scattering signal, 


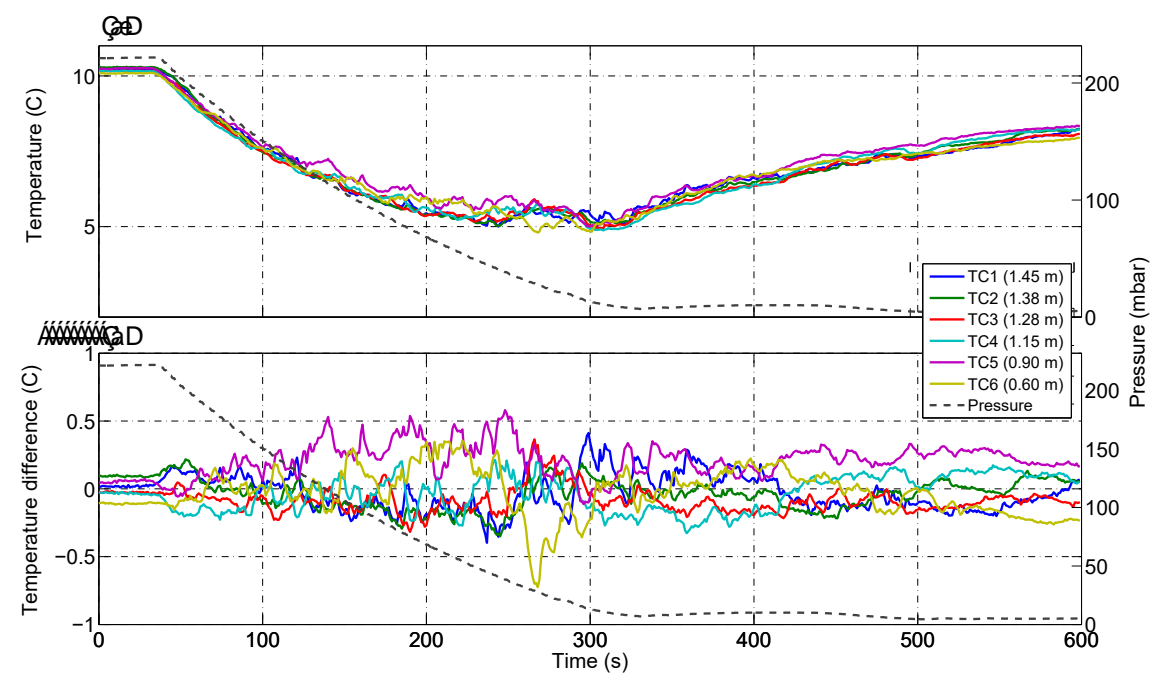

Figure 1. (a) the evolution of temperature measured by the $6 \mathrm{TC}$ before, during and after an expansion. Pressure above atmospheric pressure is also shown (dashed line, right hand axis). (b) shows the deviation of the temperature measured by each individual TC from the mean of all TC.

indicating the beginning of droplet growth. As the SIMONE measured in situ, and was not influenced by transmission effects or temperature changes in the sampling line, it is expected that this provides the most accurate way of determining the dew point and thus the LWC during the cloud periods. From the dew point temperature, the water vapour mixing ratio was calculated. A high and a low value of the dew point was also determined from the SIMONE data, based on the uncertainty in the detection time of the cloud formation with the scattering signal. The total water content of the air in the chamber was assumed to be constant over the timescale of the experiments modelled here. As aerosol growth was only observed during the cloud periods, and the dew point was determined at the beginning of each 4-6 min cloud period, the assumption of constant total water content is not expected to influence the results. This approach was validated during CLOUD9 by comparison with the TDL data. In Fig. 2, the SIMONE derived and measured peak condensed water during CLOUD9 expansions is plotted. The SIMONE derived values are calculated from the dew point determined as described above, the measured condensed water is found by taking the difference of the TDL (which only measures gas phase water) and the MBW (which measures total water after the droplets have been evaporated). From this comparison, it can be seen that the dew point and thus the total condensed water can be accurately determined using the combination of SIMONE and temperature data.

During both CLOUD8 and CLOUD9, aerosol composition (ammonium to sulphate ratio) was measured with an Aerodyne high-resolution time-of-flight aerosol mass spectrometer (HR-ToF-AMS, DeCarlo et al., 2006). To dry the sample flow, a Nafion dryer (PermaPure) was attached to the sampling line prior to the HR-ToF-AMS, and a pressure con-

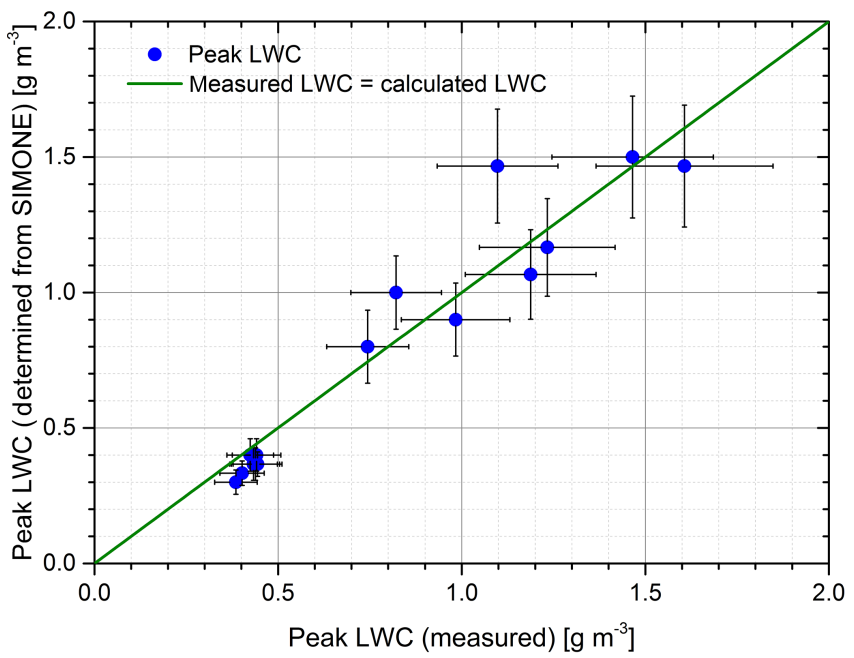

Figure 2. A comparison of the SIMONE-derived and measured (MBW total water minus TDL gas phase water) peak condensed water during CLOUD9 expansions.

trolled inlet (PCI), as described in Bahreini et al. (2008), was used to eliminate the effects of pressure variations in the sampling line on the measured concentrations.

The ionic composition of the aerosol formed is derived from HR-ToF-AMS data using the PIKA software package. A critical parameter required in the model is the ammonium to sulphate ratio (ASR) in the aerosol phase, which influences the $\mathrm{pH}$ of the cloud droplets and consequently $\mathrm{SO}_{2}$ reaction rates. The determination of this ratio heavily depends on the relative ionisation efficiencies (RIE) of ammonium and sulphate. Ammonium RIE, equal to $3.9 \pm 0.2$, was determined during the IE calibration by nebulising $\mathrm{NH}_{4} \mathrm{NO}_{3}$, 


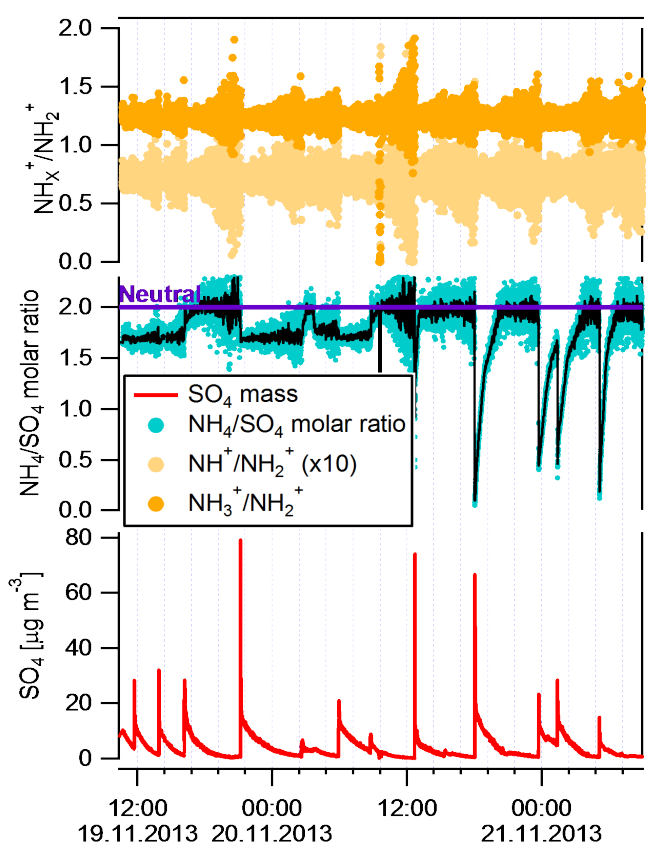

Figure 3. AMS measurements of $\mathrm{SO}_{4}$ (red line) concentrations and $\mathrm{NH}_{4} / \mathrm{SO}_{4}$ molar ratios (blue markers for raw data and black line for smoothed data). Also shown are the ratios between the main ammonium fragments, to inspect a possible interference from $\mathrm{O}^{+}$ and $\mathrm{HO}^{+}$on the determination of $\mathrm{NH}_{4}$ concentrations.

whereas the sulphate RIE, equal to $1.38 \pm 0.07$, was determined by nebulising $\left(\mathrm{NH}_{4}\right)_{2} \mathrm{SO}_{4}$. Another technical limitation that might affect the determination of ammonium concentrations is related to the possible interference of water and oxygen fragments: $\mathrm{O}^{+}$and $\mathrm{HO}^{+}$. Figure 3 displays the intensities of the main ammonium ions normalised by that of $\mathrm{NH}_{2}^{+}$. The clustering of these ratios around a single value $\left(\mathrm{NH}_{3}^{+} / \mathrm{NH}_{2}^{+}=1.23 \pm 0.05\right.$ and $\mathrm{NH}^{+} / \mathrm{NH}_{2}^{+}=0.072 \pm$ 0.008), irrespective of $\mathrm{NH}_{4}^{+}$concentration indicates that the interference from $\mathrm{O}^{+}$and $\mathrm{HO}^{+}$is negligible in our case.

Measurements of glyoxal (CHOCHO) were performed with the Light Emitting Diode Cavity Enhanced DOAS (LED-CE-DOAS). This instrument is a multispectral sensor that selectively and simultaneously measures glyoxal, oxygen collision complexes $\left(\mathrm{O}_{2}-\mathrm{O}_{2}\right)$, methyl glyoxal $\left(\mathrm{CH}_{3} \mathrm{COCHO}\right)$, nitrogen dioxide $\left(\mathrm{NO}_{2}\right)$ and other gases utilising an Ocean Optics QE65000 spectrometer (Thalman and Volkamer, 2010; Coburn et al., 2014). The detection limit of this instrument during the CLOUD9 experiment was determined to be $15-20$ pptv at the native 1 min measurement resolution employed for this study. The instrument has been extensively compared to gravitational, UV-vis and IR absorption, phosphorescence and mass spectrometric measurement techniques for alpha-dicarbonyls and $\mathrm{NO}_{2}$ (Thalman et al., 2015) and remote-sensing techniques (Volkamer et al., 2015).

\subsection{Seed aerosol formation}

Two kinds of seed aerosol were used in these experiments, pure $\mathrm{H}_{2} \mathrm{SO}_{4}$, and partially to fully neutralised ammonium sulphate aerosol. The pure $\mathrm{H}_{2} \mathrm{SO}_{4}$ aerosol was formed in an external $\mathrm{CCN}$ generator, which comprised a temperature controlled stainless steel vessel holding a ceramic crucible filled with concentrated $\mathrm{H}_{2} \mathrm{SO}_{4}$. After heating the vessel to between 150 and $180^{\circ} \mathrm{C}$, depending on the desired characteristics of the aerosol population, a flow of $\mathrm{N}_{2}$ was passed through the vessel, above the crucible to transport the hot $\mathrm{H}_{2} \mathrm{SO}_{4}$ vapour into the chamber. In addition, during CLOUD9, a humidified flow of $\mathrm{N}_{2}$ was added to the aerosol injection line immediately downstream of the $\mathrm{H}_{2} \mathrm{SO}_{4}$ vessel, to create more reproducible size distributions. As the vapour cooled in the injection line, $\mathrm{H}_{2} \mathrm{SO}_{4}$ droplets formed. The partially or fully neutralised aerosol was formed by using the same aerosol generator, and injecting $\mathrm{NH}_{3}$ directly into the chamber, where it was taken up by the acidic aerosol. The mode diameter of the aerosol distribution produced by this method was approximately $65-75 \mathrm{~nm}$, with a full width at half maximum (FWHM) of approximately $50-70 \mathrm{~nm}$.

\subsection{Experimental procedure}

A typical experiment began by pressurising the chamber to $220 \mathrm{hPa}$ above ambient pressure, and injecting $\mathrm{SO}_{2}$ and $\mathrm{O}_{3}$ so as to reach the desired mixing ratios. Seed particles were then added to the chamber, and observed for approximately 40 min to detect any growth under subsaturated conditions, before the pressure in the chamber was rapidly reduced to form the cloud. After a 15-30 min waiting time, during which the chamber temperature re-stabilised, the pressure was increased again, and further expansions were performed. This was repeated until the seed aerosol numbers decreased below a few hundred per cubic centimetre. With initial particle number densities of approximately $6000-8000 \mathrm{~cm}^{-3}$, two to four cloud cycles could usually be performed. The properties of the aerosol, cloud droplets, and gas phase species were continually measured during all stages of the experiment.

In order to better illustrate the experimental procedure, it is useful to examine some basic measurements. The SMPS measurements of the aerosol size distribution during one experiment are shown in Fig. 4. At approximately 13:00 UTC, sulphuric acid aerosol was injected into the chamber (not shown). The conditions in the chamber were held constant for approximately 2 hours, during which time the number of aerosol particles reduced due to dilution. At approximately 15:10 UTC, the first expansion was performed, and a cloud formed (marked in purple in the figure). The resulting aerosol growth can clearly be seen, both in the distribution, and from the mode diameter (line of white dots), which increases from 70 to $90 \mathrm{~nm}$. The chamber was re-pressurised and a second expansion was performed shortly after 17:00 UTC, also re- 


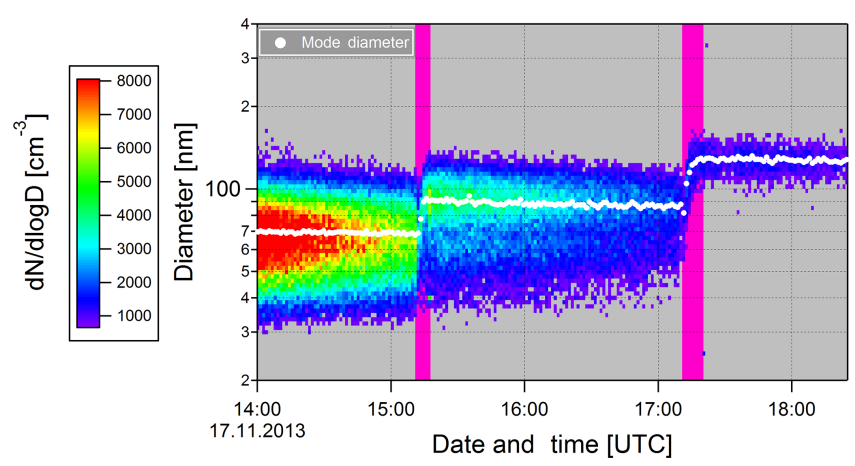

Figure 4. The aerosol size distribution measured by the SMPS attached to the total sampling line, for experiments performed on the 17 November 2013. The white line of points shows the mode diameter. Aerosol growth is clearly observed during the cloud periods (marked by the purple vertical bars).

sulting in substantial aerosol growth. No growth was observed during sub-saturated periods.

The chamber conditions for the second expansion in Fig. 4, which were used as input for the model, are shown in Fig. 5. Before the expansion, the temperature and pressure were approximately constant at $283 \mathrm{~K}$ and $1160 \mathrm{hPa}$ respectively, and the experiment was performed with approximately 18-20 ppbv $\mathrm{SO}_{2}$ and 120 ppbv $\mathrm{O}_{3}$. At approximately $600 \mathrm{~s}$ the expansion begins, and the pressure dropped, leading to an adiabatic cooling. The vertical line denotes where the SIMONE first detected the presence of water droplets, indicating that the dew point was approximately $1 \mathrm{~K}$ below the chamber temperature before the expansion started. During this expansion, the temperature reached approximately $1.5 \mathrm{~K}$ below the dew point, and the liquid water content of the air (LWC) reached a total of $0.7 \mathrm{~g} \mathrm{~m}^{-3}$. In panel $\mathrm{d}$, it can be seen that the total aerosol number concentration (the integral of the total SMPS size distribution) decreased due to the approximately $20 \%$ pressure reduction during the expansion, and due to the sedimentation and deposition of cloud droplets containing aerosol. However, before and after the expansion, the measured values remained relatively stable, with a slight decrease due to dilution. In the bottom panel of Fig. 5 the diameter of the 25 th and 75 th percentile of the particles, as well as the median diameter are plotted as a function of time. The growth in the dry aerosol diameter resulting from aqueous phase chemistry during the cloud is clearly visible. The aerosol growth occurred rapidly as the LWC increases, with growth ending soon after the LWC reached its peak.

\section{Model description}

A microphysical and chemical box model was constructed to simulate the experiments in the CLOUD chamber. The model was initialised approximately $10 \mathrm{~min}$ before each expansion with the dry aerosol size distribution measured by the SMPS attached to the total sampling line. The aerosol sizes measured by the SMPS were not adjusted to account for any remaining water present at the measurement $\mathrm{RH}$ (approximately $3 \%$ during CLOUD8 and approximately $20 \%$ during CLOUD9). This will lead to a slight overestimate of the non-water volume of aerosol during CLOUD9, however this effect is similar to the magnitude of the measurement uncertainty of the SMPS instruments (approximately $14 \%$ in volume for particles larger than $50 \mathrm{~nm}$ diameter and approximately $22 \%$ in volume for particles smaller than $50 \mathrm{~nm}$ in diameter). Subsequently, the model was integrated along a time series of data measured during the chamber experiments. Temperature and pressure, as well as the mixing ratios of $\mathrm{SO}_{2}$ and $\mathrm{O}_{3}$ were input at $1 \mathrm{~s}$ resolution, and while the actual resolution of the aerosol $\mathrm{NH}_{4}^{+}$fraction derived from the AMS data was approximately $10 \mathrm{~s}$, this was also interpolated to a $1 \mathrm{~s}$ resolution for model input. The water vapour mixing ratio for each experiment was set at the beginning of the simulation (calculated from the dew point temperature, as described in Sect. 2.3), and the sum of the gas and liquid phase water was held constant. The gas phase ammonia mixing ratio was determined for the starting time of the simulation and held constant throughout. As the gas phase ammonia mixing ratio was below the detection limit of the PTR-TOF-MS, this mixing ratio was determined using the Extended Aerosol Inorganic Model (E-AIM) (Clegg et al., 1998; Wexler and Clegg, 2002), by summing the total amount of sulphate and ammonium present in the aerosol population, and calculating the corresponding equilibrium gas phase ammonia mixing ratio under the $\mathrm{RH}$ and temperature conditions of the chamber. The validity and limitations of this approach will be discussed further in Sect. 4.2. As described below, E-AIM is also used to calculate the water activity and vapour pressure over the droplets. E-AIM has been written with the aim of reproducing the thermodynamics of the aerosol system as precisely as possible, without making compromises for the sake of computational efficiency. It is therefore considered a benchmark model (e.g. Zaveri et al., 2008).

\subsection{Aerosol water content and droplet growth}

At sub-saturated conditions, the RH in the chamber during the simulated time periods was typically above $90 \%$. At RH below $93 \%$, the hydrated aerosol was assumed to be in equilibrium with the gas phase, and the water activity was calculated, at the maximum model time step of $1 \mathrm{~s}$, using E-AIM. This calculation took into account the amount of $\mathrm{SO}_{4}^{2-}$ and $\mathrm{NH}_{4}^{+}$in the aerosol, as well as the temperature, while the pressure was held constant at $1 \mathrm{~atm}$.

Once the RH reached or exceeded $93 \%$, a full kinetic calculation of the water uptake into the aerosol or droplets was performed. The Kelvin effect was accounted for in both the equilibrium and the kinetic calculations. At $\mathrm{RH} \geq 93 \%$, the equilibrium vapour pressure of water over the aerosol or droplets, as well as the surface tension (the latter calculated 


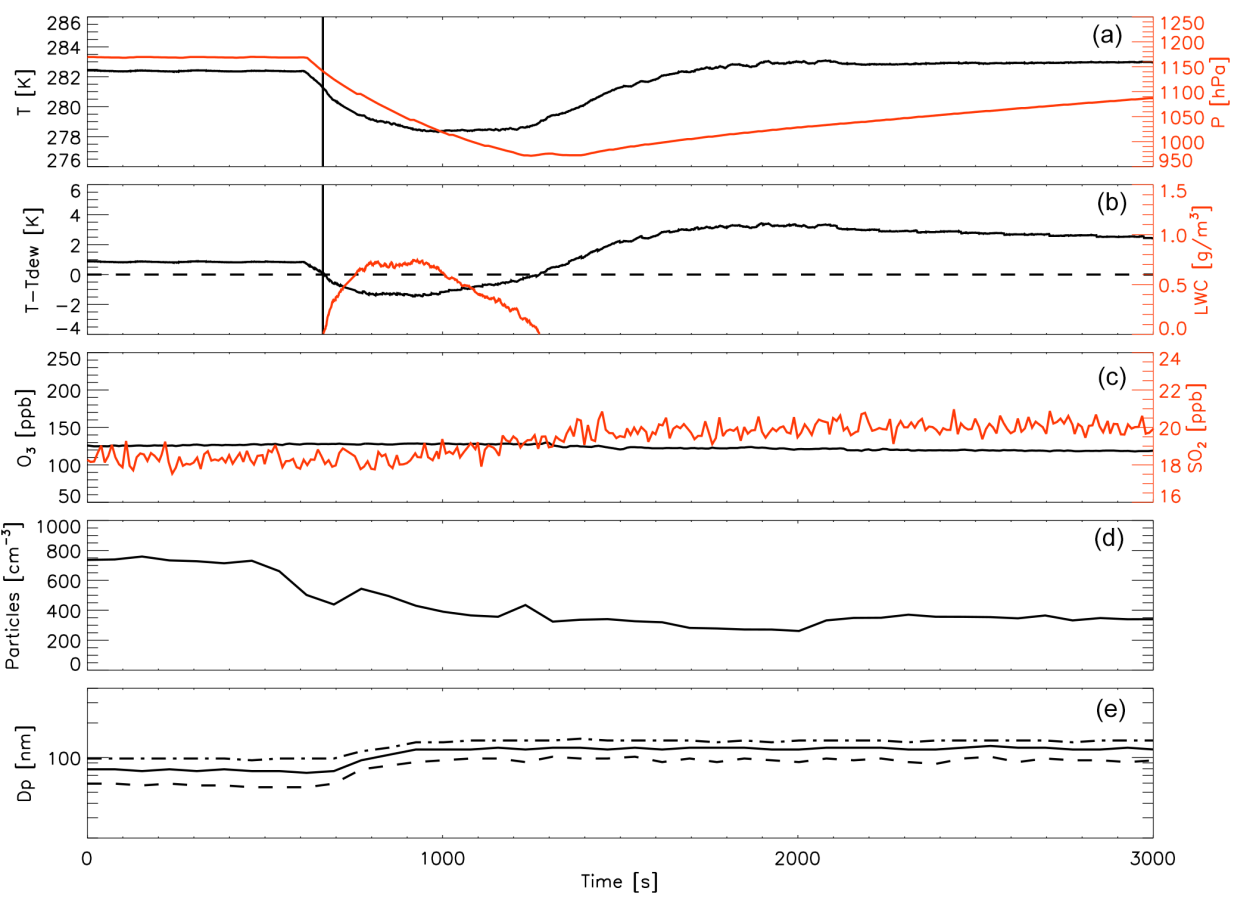

Figure 5. Measured parameters during the second expansion performed on 17 November 2013. (a) the time series of pressure and temperature, with the expansion occurring at approximately $600 \mathrm{~s}$. The resulting temperature decrease below the dew point and increase in liquid water content are shown in (b). Vertical lines in (a) and (b) indicate the time at which the SIMONE first detected enhanced forward scattering, indicating the presence of droplets. The temperature measured at this time was taken as the dew point and thus the total water content could be calculated. (c) and (d) show gas mixing ratios and the total density of particles, while (e) shows the diameter of the 25 th and 75 th percentile of particles, as well as the median diameter (dashed, dot-dashed and solid lines respectively).

in E-AIM following Dutcher et al., 2010) and the solution density were determined based on interpolation of a precalculated lookup table. The lookup table was created using E-AIM, and provides the equilibrium vapour pressure as a function of temperature, $\mathrm{NH}_{4}^{+}: \mathrm{SO}_{4}^{2-}$ ratio and $\mathrm{H}_{2} \mathrm{O}: \mathrm{SO}_{4}^{2-}$ ratio. The lookup table covers the range of $\mathrm{H}_{2} \mathrm{O}: \mathrm{SO}_{4}^{2-}$ ratios from 12 to pure water, temperature from 250 to $300 \mathrm{~K}$ and $\mathrm{NH}_{4}^{+}: \mathrm{SO}_{4}^{2-}$ ratio from 0 to 2 . The vapour pressure determined from the lookup table was then adjusted to account for the Kelvin effect. The equilibrium vapour pressure over very dilute $\mathrm{NH}_{4}^{+} / \mathrm{SO}_{4}^{2-} / \mathrm{H}_{2} \mathrm{O}$ solution droplets (assumed to be pure water) was calculated using the approach of Lowe and Ficke (1974), who parameterised the equation of Goff and Gratch (1946).

The physics of water uptake by aerosol and cloud droplets is well discussed in standard atmospheric physics textbooks, however, as this is the first time the model is described, we believe it beneficial to provide as detailed a description as possible.

When a droplet is large compared to the mean free path of water in air (continuum regime), the total flux of water to a droplet, and thus the uptake (in moles per second), is given by

$J_{c}=\frac{4 \pi R_{p} D_{g}\left(p_{\mathrm{H}_{2} \mathrm{O}}-p_{\mathrm{vap}}\right) \times 10^{-4}}{R T}$, where $R_{p}$ is the droplet radius in $\mathrm{cm}, D_{g}$ the diffusivity of water in air (in $\mathrm{cm}^{2} \mathrm{~s}^{-1}$ ), $p_{\mathrm{H}_{2} \mathrm{O}}$ the partial pressure of water vapour (in $\mathrm{hPa}$ ), $P_{\text {vap }}$ the vapour pressure of water at the droplet surface (in $\mathrm{hPa}$, calculated from the product of the equilibrium vapour pressure of water at a given temperature (Lowe and Ficke, 1974) and the activity of water in the droplet), $R$ is the gas constant $\left(8.314 \mathrm{~J} \mathrm{~mol}^{-1} \mathrm{~K}^{-1}\right)$, and $T$ is the temperature $(\mathrm{K}) . D_{g}$ is calculated as

$D_{g}=\frac{0.211 \times 1013.0}{P\left(\frac{T}{273.15}\right)^{1.94}}$,

where $P$ is the pressure in $\mathrm{hPa}$. On the other hand, small particles find themselves in the kinetic regime, with the flux (in moles per second) described by

$J_{k}=\frac{\pi R_{p}^{2} \nu \alpha\left(p_{\mathrm{H}_{2} \mathrm{O}}-p_{\text {vap }}\right) \times 10^{-4}}{R T}$,

where $\alpha$ is the mass accommodation coefficient for water (assumed to be 1.0). The mean speed of the water molecules (in $\mathrm{cm} \mathrm{s}^{-1}$ ) is given by:

$v=\left(\frac{8 \times 10^{-7} R T}{\pi M_{\mathrm{H}_{2} \mathrm{O}}}\right)^{\frac{1}{2}}$,

where $M_{\mathrm{H}_{2} \mathrm{O}}$ is the molar mass of water (in $\mathrm{g} \mathrm{mol}^{-1}$ ). 
The transition from the kinetic to continuum regime is accounted for in the model by the flux matching approach of Fuchs and Sutugin (1971):

$$
\frac{J}{J_{c}}=\frac{1+K n}{1+1.71 K n+1.33 K n^{2}}, \quad K n=\frac{\lambda}{R_{p}}, \quad \lambda=\frac{3 D_{g}}{v},
$$

where $K n$ is the Knudsen number (dimensionless) and $\lambda$ is the mean free path $(\mathrm{cm})$.

The Kelvin effect is accounted for by multiplying $p_{\text {vap }}$ by a correction factor, $C$ :

$C=\exp \frac{2 M_{\mathrm{H}_{2} \mathrm{O}} \sigma}{1 \times 10^{7} R T \rho R_{p}}$,

where $\sigma$ is the surface tension and $\rho$ is the density of the $\mathrm{H}_{2} \mathrm{O} / \mathrm{H}_{2} \mathrm{SO}_{4}$ solution at the temperature of interest.

The time step for the calculation of the water flux to or from the droplets was calculated according to the ratio between the flux and the total droplet water content, so that the droplet water content could change by no more than $2 \%$ in a single time step. The maximum time step was restricted to $1 \mathrm{~s}$.

The aerosol and the water droplets were assumed to be in thermal equilibrium with the gas phase at all times. The aerosol concentration varies linearly with the pressure in the chamber, with concentrations decreasing by around $20 \%$ during an expansion due only to the pressure change. During some expansions, particularly when the number of seed aerosol was low, the observed change in particle number concentration was larger than the modelled change, indicating that processes other than the pressure change influenced the particle loss. Corrections for both these effects are applied in the analysis.

\subsection{Chemistry}

The partitioning of $\mathrm{SO}_{2}$ and $\mathrm{O}_{3}$ to the cloud droplets, as well as the subsequent aqueous phase chemistry was calculated on a time step 100 times smaller than that for the water partitioning. Performing the analysis described by Schwartz (1988) showed that, under the conditions of the experiments presented here (even at $-10^{\circ} \mathrm{C}$ ), the partitioning of $\mathrm{SO}_{2}$ to the cloud droplets can be represented with an effective Henry's law approach, neglecting mass transport limitations. Thus the total amount of S(IV) in the droplet is given by

$[\mathrm{S}(\mathrm{IV})]=\left[\mathrm{HSO}_{3}^{-}\right]+\left[\mathrm{SO}_{3}^{2-}\right]+\left[\mathrm{SO}_{2} \cdot \mathrm{H}_{2} \mathrm{O}\right]$

with

$$
\begin{aligned}
& {\left[\mathrm{HSO}_{3}^{-}\right]=\frac{H_{\mathrm{SO}_{2}} K_{1} p_{\mathrm{SO}_{2}}}{\left[\mathrm{H}^{+}\right]},} \\
& {\left[\mathrm{SO}_{3}^{2-}\right]=\frac{H_{\mathrm{SO}_{2} K_{1} K_{2} p_{\mathrm{SO}_{2}}}\left[\mathrm{H}^{+}\right]^{2}}{}}
\end{aligned}
$$

and

$\left[\mathrm{SO}_{2} \cdot \mathrm{H}_{2} \mathrm{O}\right]=H_{\mathrm{SO}_{2}} p_{\mathrm{SO}_{2}}$ where $p_{\mathrm{SO}_{2}}$ is the gas phase partial pressure of $\mathrm{SO}_{2}, K_{1}$ and $K_{2}$ are equilibrium constants (Table 1), and $\mathrm{H}_{\mathrm{SO}_{2}}$ is the Henry's law coefficient for the dissolution of $\mathrm{SO}_{2}$ in water (Table 2). $\mathrm{H}_{2} \mathrm{SO}_{4}$ completely dissociates to $\mathrm{HSO}_{4}^{-}$and $\mathrm{H}^{+}$. The equilibrium constants given in Table 1 are taken from Seinfeld and Pandis (2006), who, in turn, reported the values recommended by Smith and Martell (1976), based on an evaluation of experimental studies conducted between 1910 and 1974. The heat of dissolution for $H_{\mathrm{SO}_{2}}$ is based on measurements between 25 and $50^{\circ} \mathrm{C}$.

The pseudo first order rate coefficient for the aqueous phase oxidation of $\mathrm{S}(\mathrm{IV})$ by $\mathrm{O}_{3}$ is

$$
\begin{aligned}
& k_{\mathrm{S}(\mathrm{IV})}=\left(k_{0} \times\left[\mathrm{SO}_{2} \cdot \mathrm{H}_{2} \mathrm{O}\right]\right)+\left(k_{1} \times\left[\mathrm{HSO}_{3}^{-}\right]\right) \\
& +\left(k_{2} \times\left[\mathrm{SO}_{3}^{2-}\right]\right),
\end{aligned}
$$

with $k_{0}, k_{1}$ and $k_{2}$ given in Table 3. Ozone, on the other hand, is subject to mass transport limitations under the experimental conditions described here, therefore, similarly to Caffrey et al. (2001), we follow the approach of Schwartz (1988), with the change in aqueous phase $\mathrm{O}_{3}$ concentration being given by

$$
\frac{\mathrm{d} C_{\mathrm{aq}}}{\mathrm{d} t}=\frac{k_{\mathrm{mt}}}{R T} p_{\mathrm{O}_{3}}-\frac{k_{\mathrm{mt}}}{H_{\mathrm{O}_{3}} R T} C_{\mathrm{aq}}-Q R_{p},
$$

with

$$
\begin{aligned}
& k_{\mathrm{mt}}=\left[\frac{R_{p}^{2} R T}{3 D_{\mathrm{g}}}+\frac{R_{p}\left(2 \pi M_{\mathrm{O}_{3}} R T\right)^{(1 / 2)}}{3 \alpha}\right]^{-1}, \\
& Q=3\left(\frac{\operatorname{coth} q}{q}-\frac{1}{q^{2}}\right),
\end{aligned}
$$

and

$q=R_{p} \sqrt{\frac{k_{\mathrm{S}(\mathrm{IV})}}{D_{\mathrm{aq}}}}$.

Here, $p_{\mathrm{O}_{3}}$ is the partial pressure of $\mathrm{O}_{3}, H_{\mathrm{O}_{3}}$ is the Henry's law coefficient for $\mathrm{O}_{3}$, measured by Kosak-Channing and Helz (1983) at temperatures between 5 and $30^{\circ} \mathrm{C}$ (Table 2) and $C_{\text {aq }}$ is the aqueous phase concentration at the surface of the droplet. The coefficient $k_{\mathrm{mt}}$ accounts for the gas and interfacial mass transport limitations. $R_{\mathrm{p}}$ is the radius of the droplet or aerosol particle, $M_{\mathrm{O}_{3}}$ is the molar mass of $\mathrm{O}_{3}$ and $\alpha$ is the mass accommodation coefficient $\left(4.0 \times 10^{-2}\right.$, Müller and Heal, 2002). In Eq. (12), $Q$, given by Eq. (14), is a correction factor to account for the lower aqueous phase concentrations of $\mathrm{O}_{3}$ caused by diffusion limited transport within the droplet. $D_{\text {aq }}$ is the aqueous phase diffusion coefficient of $\mathrm{O}_{3}$, taken as a generally representative value of $1 \times 10^{-5} \mathrm{~cm}^{2} \mathrm{~s}^{-1}$ (Schwartz, 1988), and assumed to be temperature independent. $D_{\mathrm{g}}$ is the gas phase diffusion coefficient of $\mathrm{O}_{3}$, where the typical value of $0.1 \mathrm{~cm}^{2} \mathrm{~s}^{-1}$, for a temperature of $298 \mathrm{~K}$, given by Schwartz (1986) is used as a starting point, and 
Table 1. Equilibrium constants used in the model. The temperature dependence of the equilibrium constants is given by $K=$ $K_{298} \exp \left[-\frac{\Delta H}{R}\left(\frac{1}{T}-\frac{1}{298}\right)\right]$, where $K$ is the equilibrium constant at temperature $T$ in Kelvin. $K_{1}$ refers to the equilibrium $\mathrm{SO}_{2} \cdot \mathrm{H}_{2} \mathrm{O} \rightleftharpoons$ $\mathrm{HSO}_{3}^{-}+\mathrm{H}^{+}, K_{2}$ refers to the equilibrium $\mathrm{HSO}_{3}^{-} \rightleftharpoons \mathrm{SO}_{3}^{2-}+\mathrm{H}^{+}$and $K_{3}$ to the equilibrium $\mathrm{HSO}_{4}^{-} \rightleftharpoons \mathrm{SO}_{4}^{2-}+\mathrm{H}^{+}$.

\begin{tabular}{llrl}
\hline & $K_{298}[\mathrm{M}]$ & $-\Delta H / R[\mathrm{~K}]$ & Reference \\
\hline$K_{1}$ & $1.3 \times 10^{-2}$ & 1960 & Seinfeld and Pandis (2006), Smith and Martell (1976) \\
$K_{2}$ & $6.6 \times 10^{-8}$ & 1500 & Seinfeld and Pandis (2006), Smith and Martell (1976) \\
$K_{3}$ & $1.02 \times 10^{-2}$ & 2720 & Seinfeld and Pandis (2006), Smith and Martell (1976) \\
$K_{\mathrm{NH}_{3}}$ & $1.7 \times 10^{-5}$ & -4353.09 & Seinfeld and Pandis (2006) \\
$K_{\mathrm{H}_{2} \mathrm{O}}$ & $1.0 \times 10^{-14}$ & -6710 & Seinfeld and Pandis (2006), Smith and Martell (1976) \\
\hline
\end{tabular}

Table 2. Henry's law coefficients and heats of dissolution. The temperature dependence of the coefficients is given by $H_{A}\left(T_{2}\right)=$ $H_{A}\left(T_{1}\right) \exp \left[\frac{\Delta H_{A}}{R}\left(\frac{1}{T_{1}}-\frac{1}{T_{2}}\right)\right]$.

\begin{tabular}{llll}
\hline & $H\left[\mathrm{M} \mathrm{atm}^{-1}\right.$ at $\left.298 \mathrm{~K}\right]$ & $\Delta H_{A}\left[\mathrm{kcal} \mathrm{mol}^{-1}\right.$ at $\left.298 \mathrm{~K}\right]$ & Reference \\
\hline$H_{\mathrm{O}_{3}}$ & $1.1 \times 10^{-2}$ & -5.04 & Seinfeld and Pandis (2006) \\
& & & Kosak-Channing and Helz (1983) \\
$H_{\mathrm{SO}_{2}}$ & 1.23 & -6.25 & Seinfeld and Pandis (2006) \\
& & & Pandis and Seinfeld (1989) \\
& & Smith and Martell (1976) \\
\hline
\end{tabular}

scaled for a particular temperature and pressure as follows. According to Poling et al. (2001), the value of the gas phase diffusion coefficient of a gas $\mathrm{A}$ in a second gas $\mathrm{B}$ can be calculated as

$D_{\mathrm{AB}}=\frac{0.00266 T^{3 / 2}}{P_{\mathrm{bar}} M_{\mathrm{AB}}^{1 / 2} \sigma_{\mathrm{AB}}^{2} \Omega_{\mathrm{D}}}$,

where $P_{\text {bar }}$ is the pressure in bar, $\sigma_{\mathrm{AB}}^{2}$ is a characteristic length in $\AA$, and $\Omega_{\mathrm{D}}$ is a dimensionless diffusion collision integral. Knowing the value of $D_{g}$ at a particular temperature and pressure (298 K, 1 bar) permits the calculation of a constant to represent all terms in Eq. (16), except $T$ and $P_{\text {bar }}$, enabling scaling to other temperatures and pressures:

$D_{\mathrm{g}}\left(T_{f}, P_{f}\right)=1.94 \times 10^{-5} \frac{T_{f}^{3 / 2}}{P_{f}}$,

where $T_{f}$ and $P_{f}$ are the temperature and pressure of interest.

At the beginning of the chemistry time step, the partial pressures of $\mathrm{O}_{3}$ and $\mathrm{SO}_{2}$, as well as the temperature and pressure and the AMS derived $\mathrm{NH}_{4}$ mass fraction of the aerosol from the input file were interpolated to the model time. The total $\mathrm{NH}_{4}$ mass in each aerosol particle or droplet was calculated relative to the $\mathrm{S}(\mathrm{VI})$ mass, and the $\mathrm{NH}_{4}$ and $\mathrm{S}(\mathrm{VI})$ concentrations were calculated using the water volume calculated for a particle or droplet in that size bin. Subsequently, the concentration of $\mathrm{H}^{+}$in each droplet, and thus the concentration of the other ions was calculated by iteratively solving the electroneutrality equation,

$$
\left[\mathrm{H}^{+}\right]+\left[\mathrm{NH}_{4}^{+}\right]_{\mathrm{AMS}}+\left[\mathrm{NH}_{4}^{+}\right]_{\mathrm{part}}
$$

$$
\begin{aligned}
& =\left[\mathrm{OH}^{-}\right]+\left[\mathrm{HSO}_{3}^{-}\right]+2\left[\mathrm{SO}_{3}^{2-}\right] \\
& +2\left[\mathrm{SO}_{4}^{2-}\right]+\left[\mathrm{HSO}_{4}^{-}\right],
\end{aligned}
$$

where $\left[\mathrm{NH}_{4}^{+}\right]_{\text {AMS }}$ and $\left[\mathrm{NH}_{4}^{+}\right]_{\text {part }}$ are the $\mathrm{NH}_{4}^{+}$determined from the AMS mass fraction and from the partitioning of gas phase $\mathrm{NH}_{3}$ into the cloud droplet, respectively. The latter is given by

$\left[\mathrm{NH}_{4}^{+}\right]_{\text {part }}=H_{\mathrm{NH}_{3}} \times p_{\mathrm{NH}_{3}} \times K_{\mathrm{NH}_{3}} \times\left[\mathrm{H}^{+}\right] / K_{\mathrm{H}_{2} \mathrm{O}}$,

with $p_{\mathrm{NH}_{3}}$ being the gas phase partial pressure of $\mathrm{NH}_{3}$, and the remaining constants defined in Tables 1 and 2 .

In Eq. (18), $\left[\mathrm{HSO}_{3}^{-}\right]$is given by Eq. (8), $\left[\mathrm{SO}_{3}^{2-}\right]$ by Eq. (9), $\left[\mathrm{SO}_{4}^{2-}\right]$ by

$\left[\mathrm{SO}_{4}^{2-}\right]=\frac{K_{3}[\mathrm{~S}(\mathrm{VI})]}{\left[\mathrm{H}^{+}\right]+K_{3}}$

and $\left[\mathrm{HSO}_{4}^{-}\right]$by

$\left[\mathrm{HSO}_{4}^{-}\right]=\frac{\left[\mathrm{H}^{+}\right][\mathrm{S}(\mathrm{VI})]}{\left[\mathrm{H}^{+}\right]+K_{3}}$.

Once the concentrations of the ions are known, the production of S(VI) is calculated from

$\Delta \mathrm{S}(\mathrm{VI})=Q k_{\mathrm{S}(\mathrm{IV})}\left[\mathrm{O}_{3}\right]_{\mathrm{aq}} \mathrm{d} t$.

The new aqueous phase $\mathrm{O}_{3}$ concentration is calculated using a backward Eulerian approach to solve Eq. (12), so that 


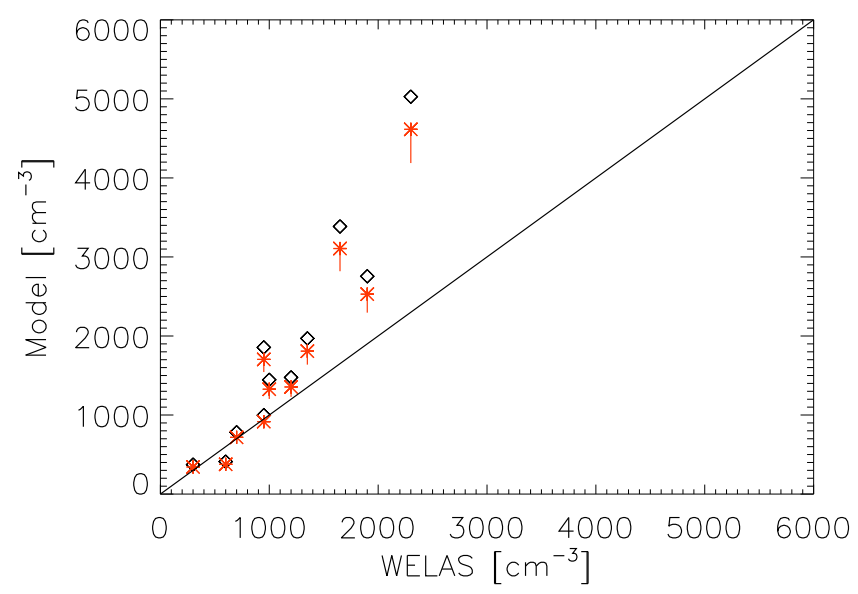

Figure 6. The number of cloud droplets formed in the model (orange stars) and the number of aerosol immediately before the expansion (black diamonds), plotted against the maximum number of droplets detected by WELAS during the presence of the cloud. The error bars on the modelled droplet numbers correspond to simulations using the high and low values of the dew point calculated from the SIMONE data. Data are shown for all CLOUD9 experiments where data were available.

a relatively long time step can be used without large fluctuations in $\left[\mathrm{O}_{3}\right]_{\mathrm{aq}}$ which could lead to values that are negative, or exceed the maximum concentration determined by Henry's law.

\section{Results}

Data from a total of 31 expansions were analysed, 15 at $10{ }^{\circ} \mathrm{C}$, and 16 at $-10^{\circ} \mathrm{C}$. Table 4 lists the most important data describing the different experiments and model runs. $\mathrm{SO}_{2}$ mixing ratios ranged from 0.9 to $26.4 \mathrm{ppbv}$, and $\mathrm{O}_{3}$ from 63.5 to $137.2 \mathrm{ppbv}$.

\subsection{Aerosol activation and cloud droplets}

Peak LWCs of up to $1.5 \mathrm{~g} \mathrm{~m}^{-3}$ were seen during the $10^{\circ} \mathrm{C}$ experiments, and the largest size reached by the median droplets in the modelled size distribution was $17 \mu \mathrm{m}$, with the smallest being $4.9 \mu \mathrm{m}$. Most of the aerosol particles were activated during the expansions, with modelled activated fractions generally being around 0.9 . In one case, however, only $34 \%$ of the aerosol particles were activated.

The number of modelled cloud droplets (defined as the number of droplets larger than $1 \mu \mathrm{m}$ in diameter; orange symbols) is compared with the number measured by the WELAS, in Fig. 6, for several of the CLOUD9 experiments. WELAS data from two of the CLOUD9 experiments, and from the CLOUD8 experiments were not available. At aerosol numbers below $1000 \mathrm{~cm}^{-3}$, all aerosol are activated, and the modelled number of droplets matches the number of droplets detected by the WELAS. At higher aerosol concentrations, the modelled and measured numbers of droplets diverge, with the modelled number being higher than that measured by the WELAS. The LWC calculated from the WELAS data is sometimes lower than the LWC derived from the SIMONE, TDL and MBW data, which may explain part of the discrepancy between modelled and WELAS-measured droplet numbers. Further, cooling in the chamber is unlikely to be totally homogeneous, possibly resulting in slightly differing activated fractions of aerosol in different regions of the chamber in the initial stages of the expansion. Much of the clear relationship between the modelled droplet number and that measured by the WELAS can likely be explained by the fact that both depend strongly on the number of aerosol in the chamber (black diamonds in Fig. 6), nevertheless it is encouraging that the modelled and measured droplet numbers are well correlated.

\subsection{Ammonia in the CLOUD chamber}

At this point, it is useful to examine the assumptions made with regard to the gas phase ammonia, and the amount of ammonium in the aerosol and the cloud droplets in greater detail. In Sect. 3, it was stated that the ASR of the aerosol were measured using an AMS, that these ratios were then used to determine the gas phase ammonia in the chamber, using EAIM, and that the uptake of this ammonia to cloud droplets was calculated assuming that the droplets were in an effective Henry's law equilibrium with a constant gas phase ammonia concentration. For this approach to be accurate, a number of conditions must be met, each of which are discussed in the subsections below. We find that the pre-expansion determination of the gas phase ammonia mixing ratio is likely to be correct, as is the assumption that the ammonium concentration in the droplets is in equilibrium with the gas phase ammonia. However, the gas phase ammonia mixing ratio during the cloud periods cannot generally be assumed to be constant.

\subsubsection{Accuracy of AMS measurement of ammonia in hydrated aerosol}

Firstly, the ammonium to sulphate ratio in the particles must be accurately measured by the AMS. Some technical aspects of this measurement were already discussed in Sect. 2.3. The $\mathrm{NH}_{4}^{+}: \mathrm{SO}_{4}^{2-}$ ratio used to determine the gas phase ammonia mixing ratio was measured during the subsaturated period immediately preceding each expansion, when the RH in the chamber was approximately $95 \%$. The calculation of the gas phase ammonia was carried out with E-AIM, using the AMS determined $\mathrm{NH}_{4}^{+}: \mathrm{SO}_{4}^{2-}$ ratio, at a pressure of one atmosphere and the temperature and $\mathrm{RH}$ conditions measured in the chamber. Any reduction in $\mathrm{NH}_{4}^{+}: \mathrm{SO}_{4}^{2-}$ ratio due to processes such as the drying of the air on the way to the AMS would lead to a lower calculated gas phase ammonia mixing ratio (Fig. 7). Calculations with E-AIM show that under the assumption of a metastable aqueous phase, without the for- 


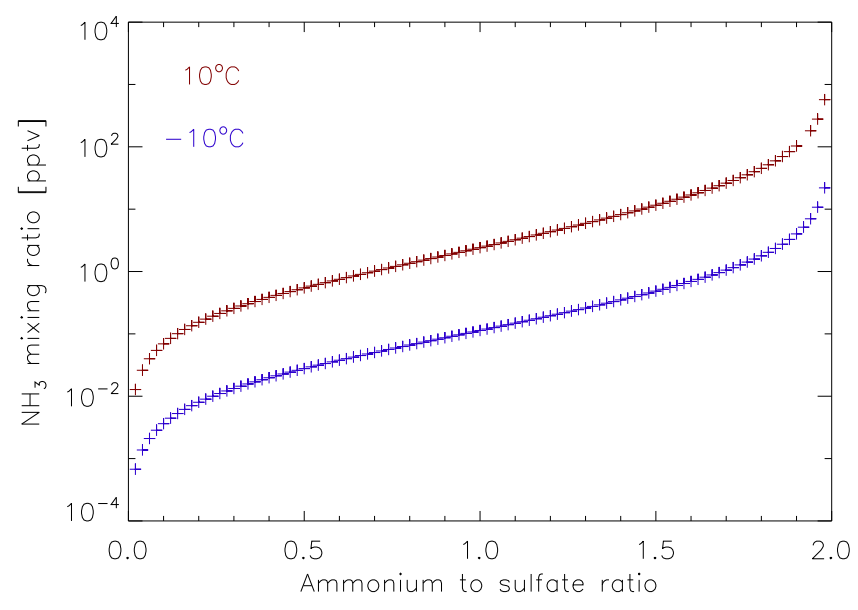

Figure 7. The equilibrium gas phase ammonia mixing ratio, calculated with E-AIM, as a function of the ammonium to sulphate ratio of the aerosol. Data shown are for -10 and $10^{\circ} \mathrm{C}$, at $\mathrm{RH}=95 \%$.

mation of solids, the $\mathrm{NH}_{4}^{+}: \mathrm{SO}_{4}^{2-}$ ratio can be reduced from 2 to 1.5 during a change in $\mathrm{RH}$ from 95 to $35 \%$. If solid phases are allowed to form however, the $\mathrm{NH}_{4}^{+}: \mathrm{SO}_{4}^{2-}$ ratio is much less sensitive to changes in RH. It has been observed that ammonium sulphate particles bounce from the AMS vapouriser, therefore we expect that ammonium sulphate is in a solid state and that there are minimal ammonium losses during the drying process.

In a recent study, nebulised mixtures of ammonium sulphate and ammonium nitrate were measured with an AMS (nitrate activity coefficients of $0,0.3,0.5,0.7$ and 1 ). It was found that the AMS reliably measures the predicted ammonium content of the mixtures of these internally mixed ammonium nitrate and ammonium sulphate particles (Xu et al., 2016). We are not aware of any analogous study for aerosol containing only varying ratios of ammonium and sulphate, however if ammonia is not lost from the mixtures described above during the measurement process, we do not expect that it will be lost from aerosol formed from pure ammonium and sulphate solution. Therefore it is likely that the AMS determined ammonium to sulphate ratios are correct.

\subsubsection{Uptake of ammonia by a droplet}

Since it is possible to estimate the gas phase ammonia before the expansion and cloud formation from the AMS measurements with a reasonable degree of accuracy, the next question is whether or not our assumption of an effective Henry's law equilibrium between droplet and gas phase ammonia is accurate. Using an experiment with a relatively high gas phase ammonia concentration as an example (CLD8_20_11_1b), the uptake of ammonia by a $7 \mu \mathrm{m}$ diameter water droplet was calculated, under the assumption that the droplet initially contained no ammonium, and was exposed to a 22 pptv am-

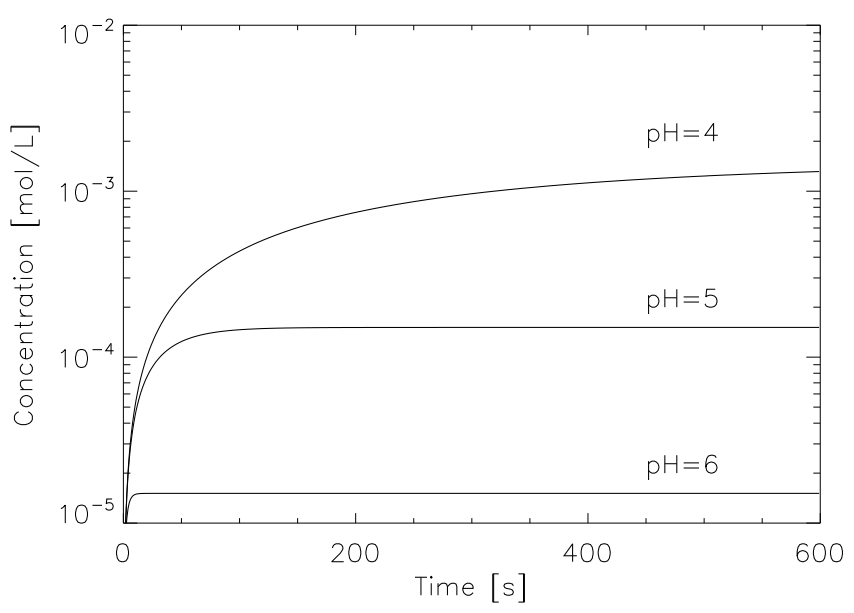

Figure 8. The aqueous phase concentration of $\mathrm{NH}_{4}^{+}$in a $7 \mu \mathrm{m}$ diameter water droplet, exposed to a 22 pptv $\mathrm{NH}_{3}$ gas phase, similar to the conditions of experiment CLD8_20_11_1b.

monia gas phase. The development of the droplet ammonium concentration with time is plotted in Fig. 8, for three different solution $\mathrm{pH}$. At the lowest, $\mathrm{pH}=4$, equilibrium is reached after approximately $600 \mathrm{~s}$, which is comparable with the time scale of the clouds formed in the chamber (400-600 s). At higher $\mathrm{pH}$, the timescale becomes shorter very rapidly. As shown in Table 4, for most of the experiments, the $\mathrm{pH}$ lay between 4 and 5 . We therefore expect that the ammonium concentration in the droplets will be essentially equal to the values predicted by assuming an effective Henry's law equilibrium with the gas phase.

\subsubsection{Assumption of constant gas phase ammonia}

The assumption that the gas phase ammonia is constant during the cloud formation is more difficult to constrain. As shown in Table 5, under the assumption of a constant gas phase, and droplet equilibrium with the gas phase, the amount of ammonia that was taken up into the cloud droplets suspended in a cubic centimetre of air was between approximately 12 and 2500 times the gas phase amount in that same air volume. The experiments with the highest values of this ratio were the ones performed under essentially acidic conditions, such that ammonia was almost absent from the gas phase. The results of these experiments are therefore not sensitive to uncertainties in the gas phase ammonia concentration.

For the experiments with near neutral seed aerosol (for example CLD8_20_11_2a), the droplets would have needed to take up around 500 times the gas phase ammonia in order for our assumption of droplet equilibrium with a constant gas phase to hold. The only possible sources of ammonia in the chamber during the cloud formation were the chamber walls, any water in the bottom of the chamber or the particles themselves. The total wall area of the chamber is approxi- 
Table 3. Rate constants for the aqueous phase oxidation of S(IV) with dissolved ozone, used in Eq. (11). The temperature dependence of the rate constants is given by $k(T)=\frac{k_{298}}{\exp \left[-\frac{E}{R}\left(\frac{1}{298}-\frac{1}{T}\right)\right]}$. The activation energies given for the $k_{1}$ and $k_{2}$ values are those of Erickson et al. (1977), based on measurements at 16 and $25^{\circ} \mathrm{C}$.

\begin{tabular}{llll}
\hline & $K_{298}\left[\mathrm{M}^{-1} \mathrm{~s}^{-1}\right]$ & $-E / R[\mathrm{~K}]$ & Reference \\
\hline$k_{0}$ & $2.4 \times 10^{4}$ & 0 & Seinfeld and Pandis (2006), Hoffmann (1986) \\
$k_{1}$ & $3.7 \times 10^{5}$ & -5530 & Seinfeld and Pandis (2006), Hoffmann (1986) \\
$k_{2}$ & $1.5 \times 10^{9}$ & -5280 & Seinfeld and Pandis (2006), Hoffmann (1986) \\
\hline
\end{tabular}

Table 4. A list of the measured and modelled conditions during each experiment. $T_{i}$ is the temperature just before the expansion, and $T_{\min }$ is the minimum temperature measured during the expansion. Peak LWC is the maximum condensable water during the expansion, derived from the dew point temperature $\left(T_{\mathrm{dew}}\right)$ and $T_{\min }$. The median drop diameter (modelled) is the largest size reached by the median drop during the expansion and the median dry diameter is taken from the model output just prior to the expansion. The maximum activated fraction is the maximum modelled number of droplets larger than $1 \mu \mathrm{m}$ in diameter during the expansion, divided by the total number of aerosol. The change in measured volume divided by the change in modelled volume is the numerical value for the points plotted in Fig. 11. The maximum $\mathrm{pH}$ is the maximum $\mathrm{pH}$ reached by the median sized droplet during the expansion (modelled), the $\mathrm{NH}_{4}^{+} / \mathrm{SO}_{4}^{2-}$ molar ratio is calculated from the AMS data just prior to the expansion. The gas phase ammonia mixing ratio was calculated from the AMS data immediately prior to the expansion, as described in Sect. 3 and the number of aerosol is the modelled number of aerosol just prior to the expansion.

\begin{tabular}{|c|c|c|c|c|c|c|c|c|c|c|c|c|c|c|c|}
\hline Run & $\begin{array}{l}\text { Stage } \\
\text { number }\end{array}$ & $\begin{array}{l}\mathrm{SO}_{2} \\
\text { [ppbv] }\end{array}$ & $\begin{array}{l}\mathrm{O}_{3} \\
{[\mathrm{ppbv}]}\end{array}$ & $\begin{array}{l}T_{i} \\
{[\mathrm{~K}]}\end{array}$ & $\begin{array}{l}T_{\min } \\
{[\mathrm{K}]}\end{array}$ & $\begin{array}{l}T_{\text {dew }} \\
{[\mathrm{K}]}\end{array}$ & $\begin{array}{l}\text { Peak LWC } \\
{\left[\mathrm{g} \mathrm{m}^{-3}\right]}\end{array}$ & $\begin{array}{l}\text { Median drop } \\
\text { Diameter } \\
{[\mu \mathrm{m}]}\end{array}$ & $\begin{array}{l}\text { Median dry } \\
\text { Diameter } \\
{[\mathrm{nm}]}\end{array}$ & $\begin{array}{l}\text { max. } \\
\text { activated } \\
\text { fraction }\end{array}$ & $\begin{array}{l}\Delta \text { Meas. vol/ } \\
\Delta \text { Mod. vol }\end{array}$ & $\max \mathrm{pH}$ & $\begin{array}{l}\mathrm{NH}_{4}^{+} / \mathrm{SO}_{4}^{2-} \\
\text { molar ratio }\end{array}$ & $\begin{array}{l}\mathrm{NH}_{3}(\mathrm{~g}) \\
\text { pptv }\end{array}$ & $\mathrm{N}_{\text {aerosol }}$ \\
\hline CLD8_17_11_1a & 1243.04 & 17.4 & 82.3 & 282.3 & 277.6 & 281.0 & 0.9 & 9.8 & 66.1 & 0.92 & 0.84 & 4.37 & 0.03 & 0.0142 & 2100.35 \\
\hline CLD8_17_11_1b & 1243.06 & 18.3 & 125.8 & 282.4 & 278.4 & 281.2 & 0.8 & 13.4 & 79.6 & 0.92 & 0.53 & 4.28 & 0.03 & 0.0123 & 732.06 \\
\hline CLD8_18_11_1b & 1245.03 & 19.9 & 126.5 & 282.5 & 278.5 & 280.8 & 0.5 & 8.6 & 66.5 & 0.73 & 0.69 & 4.24 & 0.02 & 0.0377 & 2288.45 \\
\hline CLD8_20_11_1a & 1249.03 & 1.3 & 136.3 & 282.3 & 278.0 & 281.3 & 0.9 & 8.7 & 76.4 & 0.87 & 2.33 & 5.55 & 1.58 & 13.0602 & 3041.92 \\
\hline CLD8_20_11_1b & 1249.09 & 2.3 & 137.2 & 282.3 & 278.5 & 281.7 & 0.9 & 6.9 & 88.2 & 0.95 & 1.25 & 5.55 & 1.67 & 21.5740 & 6323.98 \\
\hline CLD8_20_11_2a & 1250.11 & 23.7 & 136.8 & 262.7 & 258.4 & 261.8 & 0.3 & 5.1 & 71.0 & 0.95 & 1.75 & 4.49 & 1.87 & 1.4404 & 5628.41 \\
\hline CLD8_20_11_2b & 1251.04 & 26.6 & 128.9 & 262.3 & 258.5 & 261.5 & 0.3 & 4.9 & 91.4 & 0.90 & 0.40 & 4.57 & 1.88 & 2.5927 & 6309.59 \\
\hline CLD8_20_11_2c & 1251.09 & 21.0 & 126.9 & 262.4 & 258.5 & 261.4 & 0.3 & 7.0 & 113.3 & 0.90 & 1.01 & 4.47 & 1.85 & 1.1498 & 1874.42 \\
\hline CLD8_21_11_1a & 1252.04 & 18.3 & 115.3 & 262.3 & 258.3 & 261.6 & 0.3 & 6.0 & 81.9 & 0.96 & 0.66 & 4.48 & 1.87 & 1.0562 & 3213.07 \\
\hline CLD8_21_11_1b & 1252.12 & 18.5 & 115.4 & 262.3 & 258.5 & 261.7 & 0.3 & 5.0 & 82.1 & 0.98 & 0.56 & 4.52 & 1.80 & 1.3962 & 4322.27 \\
\hline CLD8_21_11_1c & 1252.17 & 19.8 & 118.8 & 262.5 & 258.5 & 261.5 & 0.3 & 7.2 & 101.8 & 0.96 & 0.83 & 4.42 & 1.69 & 0.7903 & 1632.21 \\
\hline CLD8_05_12_1a & 1306.20 & 1.1 & 92.4 & 282.7 & 278.8 & 281.6 & 0.6 & 9.8 & 53.2 & 0.34 & 0.94 & 5.79 & 1.75 & 21.1771 & 3920.10 \\
\hline CLD8_05_12_1b & 1306.27 & 0.9 & 131.0 & 282.8 & 278.9 & 281.6 & 0.6 & 11.6 & 71.1 & 0.59 & 0.65 & 5.70 & 1.74 & 24.2970 & 1341.82 \\
\hline CLD8_07_12_1a & 1310.14 & 19.6 & 107.1 & 262.6 & 259.0 & 261.5 & 0.2 & 5.5 & 71.2 & 0.92 & 6.15 & 4.25 & 1.24 & 0.2614 & 2672.03 \\
\hline CLD8_07_12_1b & 1310.17 & 10.3 & 178.1 & 262.6 & 259.2 & 261.6 & 0.2 & 7.3 & 109.6 & 0.96 & 3.62 & 4.23 & 1.21 & 0.1665 & 1086.43 \\
\hline CLD8_07_12_1c & 1310.23 & 10.2 & 203.9 & 262.5 & 259.0 & 261.5 & 0.2 & 6.8 & 88.5 & 0.90 & 2.66 & 4.21 & 0.85 & 0.1085 & 1440.50 \\
\hline CLD9_24_09_2b & 1418.11 & 18.5 & 112.8 & 283.4 & 279.2 & 282.4 & 0.8 & 8.1 & 66.0 & 0.86 & 0.41 & 4.40 & 0.61 & 0.5036 & 3492.84 \\
\hline CLD9_24_09_2c & 1418.15 & 19.4 & 115.6 & 283.4 & 279.1 & 282.9 & 1.0 & 10.6 & 76.2 & 0.90 & 0.25 & 4.44 & 0.84 & 0.6745 & 1794.43 \\
\hline CLD9_25_09_1a & 1422.05 & 29.2 & 90.8 & 283.7 & 278.3 & 282.2 & 0.9 & 10.1 & 98.8 & 0.98 & 0.39 & 4.41 & 0.92 & 1.7512 & 1856.36 \\
\hline CLD9_25_09_1b & 1422.08 & 26.4 & 85.8 & 284.0 & 278.7 & 282.3 & 1.0 & 12.1 & 112.0 & 0.97 & 0.66 & 4.36 & 0.89 & 0.5860 & 998.07 \\
\hline CLD9_25_09_1c & 1422.12 & 25.4 & 73.9 & 284.8 & 278.7 & 282.6 & 1.1 & 17.0 & 136.4 & 1.00 & 0.63 & 4.32 & 0.55 & 0.2159 & 410.01 \\
\hline CLD9_25_09_2a & 1422.15 & 25.0 & 63.5 & 283.8 & 278.6 & 283.1 & 1.4 & 8.6 & 75.7 & 0.86 & 0.43 & 4.35 & 0.77 & 0.6497 & 5028.45 \\
\hline CLD9_25_09_2b & 1422.17 & 25.1 & 89.2 & 284.2 & 277.9 & 282.9 & 1.5 & 10.7 & 91.6 & 0.89 & 0.39 & 4.35 & 0.58 & 0.7761 & 2756.07 \\
\hline CLD9_25_09_2c & 1422.20 & 25.0 & 84.9 & 284.1 & 277.8 & 282.9 & 1.4 & 12.7 & 113.0 & 0.92 & 0.42 & 4.42 & 1.01 & 1.3842 & 1476.15 \\
\hline CLD9_28_09_1a & 1434.11 & 17.5 & 85.3 & 262.3 & 257.7 & 260.8 & 0.3 & 5.7 & 82.2 & 0.94 & 2.06 & 3.91 & 0.28 & 0.0098 & 3385.48 \\
\hline CLD9_28_09_1b & 1434.13 & 20.4 & 92.8 & 263.3 & 257.9 & 261.7 & 0.4 & 6.8 & 88.1 & 0.97 & 1.64 & 3.97 & 0.32 & 0.0093 & 1970.34 \\
\hline CLD9_28_09_1c & 1434.16 & 22.9 & 109.4 & 263.3 & 258.0 & 261.9 & 0.4 & 8.7 & 99.1 & 0.98 & 1.31 & 4.02 & 0.43 & 0.0124 & 1149.79 \\
\hline CLD9_28_09_1d & 1434.19 & 21.8 & 112.2 & 263.4 & 258.1 & 261.9 & 0.4 & 10.5 & 113.6 & 0.99 & 1.27 & 4.04 & 0.63 & 0.0174 & 595.93 \\
\hline CLD9_28_09_2a & 1435.04 & 15.5 & 107.2 & 263.5 & 258.1 & 261.8 & 0.3 & 8.3 & 49.7 & 0.92 & 0.56 & 4.17 & 0.10 & 0.0081 & 1445.49 \\
\hline CLD9_28_09_2b & 1435.06 & 7.6 & 109.1 & 263.1 & 257.9 & 261.8 & 0.4 & 9.4 & 73.9 & 0.96 & 0.31 & 4.29 & 0.92 & 0.0176 & 782.26 \\
\hline CLD9_28_09_2c & 1435.09 & 4.0 & 111.9 & 263.2 & 257.7 & 261.7 & 0.4 & 11.9 & 88.1 & 0.95 & 0.40 & 4.37 & 0.71 & 0.0077 & 373.06 \\
\hline
\end{tabular}

mately $42 \mathrm{~m}^{2}$, which is comparable to the total surface area of the droplets $\left(8.5 \mathrm{~m}^{2}\right.$ for $10 \mu \mathrm{m}$ diameter droplets at a concentration of $1000 \mathrm{~cm}^{-3}, 34 \mathrm{~m}^{2}$ for $20 \mu \mathrm{m}$ diameter droplets at a concentration of $1000 \mathrm{~cm}^{-3}$ ). Before the expansion, the walls were in equilibrium with the gas phase and the particles (no changes in the $\mathrm{NH}_{4}^{+}: \mathrm{SO}_{4}^{2-}$ ratio of the particles were observed before the expansion, unless further ammonia was injected into the chamber), being coated in a mixture of ammonium, sulphuric acid and water. During the expansion, the walls maintained a constant temperature, while the temperature of the gas in the chamber decreased.
The uptake of gases on chamber walls was investigated by McMurry and Grosjean (1985), who pointed out that when the accommodation coefficient of the gas on the chamber walls is high (in their case higher than approximately $6 \times$ $10^{-6}$ ), transport is diffusion-limited, with the rate of diffusion also depending on the turbulence in the chamber (parameterised by an eddy diffusion coefficient). For their Teflon chamber, they find an accommodation coefficient of $1.2-4.8 \times 10^{-8}$ for ammonia, suggesting that exchange with the walls occurs even more slowly than the rate of diffusion. For the CLOUD chamber, previous measurements have 
Table 5. Data from the model simulations, showing the gas phase concentration of ammonia, the total particle phase ammonium contained in all particles in one $\mathrm{cm}^{3}$ of air before cloud formation, and the maximum additional amount of ammonium taken up into all droplets in one $\mathrm{cm}^{3}$ of air during the cloud formation. Values in brackets indicate the ratio of the number of moles of ammonium contained in the particles or droplets to the gas phase ammonia concentration. The first three columns are reproduced from Table 4, for convenience. Note that the aqueous phase ammonium is in addition to the particle phase ammonium, which is also contained in any droplets that form.

\begin{tabular}{|c|c|c|c|c|c|c|}
\hline Run & $\begin{array}{l}\text { Stage } \\
\text { number }\end{array}$ & $\begin{array}{l}\mathrm{NH}_{4}^{+} / \mathrm{SO}_{4}^{2-} \\
\text { [molar ratio] }\end{array}$ & $\begin{array}{l}\mathrm{NH}_{3}(\mathrm{~g}) \\
{[\mathrm{pptv}]}\end{array}$ & $\begin{array}{l}\mathrm{NH}_{3}(\mathrm{~g}) \\
{\left[\mathrm{mol} \mathrm{cm}^{-3}\right]}\end{array}$ & $\begin{array}{l}\mathrm{NH}_{4}^{+} \text {(particle) } \\
{\left[\mathrm{mol} \mathrm{cm}^{-3}\right], \text { (ratio) }}\end{array}$ & $\begin{array}{l}\mathrm{NH}_{4}^{+}(\mathrm{aq}, \text { peak }) \\
{\left[\mathrm{mol} \mathrm{cm}^{-3}\right], \text { (ratio) }}\end{array}$ \\
\hline CLD8_17_11_1a & 1243.04 & 0.03 & 0.0142 & $7.05 \times 10^{-19}$ & $5.86 \times 10^{-16}(830.32)$ & $3.86 \times 10^{-16}(547.13)$ \\
\hline CLD8_17_11_1b & 1243.06 & 0.03 & 0.0123 & $6.11 \times 10^{-19}$ & $2.62 \times 10^{-16}(428.41)$ & $2.63 \times 10^{-16}(430.42)$ \\
\hline CLD8_18_11_1b & 1245.03 & 0.02 & 0.0377 & $1.88 \times 10^{-18}$ & $9.32 \times 10^{-16}(496.51)$ & $9.83 \times 10^{-16}(523.54)$ \\
\hline CLD8_20_11_1a & 1249.03 & 1.58 & 13.0602 & $6.50 \times 10^{-16}$ & $4.14 \times 10^{-14}(63.70)$ & $1.65 \times 10^{-14}(25.37)$ \\
\hline CLD8_20_11_1b & 1249.09 & 1.67 & 21.5740 & $1.07 \times 10^{-15}$ & $1.41 \times 10^{-13}(131.59)$ & $3.26 \times 10^{-14}(30.38)$ \\
\hline CLD8_20_11_2a & 1250.11 & 1.87 & 1.4404 & $7.71 \times 10^{-17}$ & $7.23 \times 10^{-14}(937.81)$ & $3.89 \times 10^{-14}(504.72)$ \\
\hline CLD8_20_11_2b & 1251.04 & 1.88 & 2.5927 & $1.39 \times 10^{-16}$ & $1.87 \times 10^{-13}(1342.01)$ & $6.33 \times 10^{-14}(455.78)$ \\
\hline CLD8_20_11_2c & 1251.09 & 1.85 & 1.1498 & $6.16 \times 10^{-17}$ & $7.20 \times 10^{-14}(1167.93)$ & $3.18 \times 10^{-14}(515.48)$ \\
\hline CLD8_21_11_1a & 1252.04 & 1.87 & 1.0562 & $5.66 \times 10^{-17}$ & $7.22 \times 10^{-14}(1274.75)$ & $3.20 \times 10^{-14}(564.51)$ \\
\hline CLD8_21_11_1b & 1252.12 & 1.80 & 1.3962 & $7.48 \times 10^{-17}$ & $7.55 \times 10^{-14}(1008.44)$ & $2.93 \times 10^{-14}(391.31)$ \\
\hline CLD8_21_11_1c & 1252.17 & 1.69 & 0.7903 & $4.23 \times 10^{-17}$ & $4.04 \times 10^{-14}(953.98)$ & $2.43 \times 10^{-14}(574.69)$ \\
\hline CLD8_05_12_1a & 1306.20 & 1.75 & 21.1771 & $1.07 \times 10^{-15}$ & $4.85 \times 10^{-14}(45.31)$ & $1.33 \times 10^{-14}(12.38)$ \\
\hline CLD8_05_12_1b & 1306.27 & 1.74 & 24.2970 & $1.23 \times 10^{-15}$ & $5.58 \times 10^{-14}(45.46)$ & $1.43 \times 10^{-14}(11.67)$ \\
\hline CLD8_07_12_1a & 1310.14 & 1.24 & 0.2614 & $1.42 \times 10^{-17}$ & $4.03 \times 10^{-14}(2829.00)$ & $1.19 \times 10^{-14}(839.10)$ \\
\hline CLD8_07_12_1b & 1310.17 & 1.21 & 0.1665 & $9.07 \times 10^{-18}$ & $2.88 \times 10^{-14}(3172.37)$ & $6.87 \times 10^{-15}(757.97)$ \\
\hline CLD8_07_12_1c & 1310.23 & 0.85 & 0.1085 & $5.91 \times 10^{-18}$ & $2.64 \times 10^{-14}(4464.63)$ & $6.56 \times 10^{-15}(1109.05)$ \\
\hline CLD9_24_09_2b & 1418.11 & 0.61 & 0.5036 & $2.55 \times 10^{-17}$ & $1.15 \times 10^{-14}(450.25)$ & $1.76 \times 10^{-15}(68.79)$ \\
\hline CLD9_24_09_2c & 1418.15 & 0.84 & 0.6745 & $3.42 \times 10^{-17}$ & $8.48 \times 10^{-15}(247.82)$ & $9.17 \times 10^{-15}(268.19)$ \\
\hline CLD9_25_09_1a & 1422.05 & 0.92 & 1.7512 & $8.87 \times 10^{-17}$ & $2.44 \times 10^{-14}(275.10)$ & $2.40 \times 10^{-14}(270.27)$ \\
\hline CLD9_25_09_1b & 1422.08 & 0.89 & 0.5860 & $2.97 \times 10^{-17}$ & $1.20 \times 10^{-14}(403.80)$ & $1.31 \times 10^{-15}(44.29)$ \\
\hline CLD9_25_09_1c & 1422.12 & 0.55 & 0.2159 & $1.09 \times 10^{-17}$ & $5.05 \times 10^{-15}(463.43)$ & $6.33 \times 10^{-16}(58.07)$ \\
\hline CLD9_25_09_2a & 1422.15 & 0.77 & 0.6497 & $3.29 \times 10^{-17}$ & $2.66 \times 10^{-14}(808.86)$ & $3.81 \times 10^{-15}(115.77)$ \\
\hline CLD9_25_09_2b & 1422.17 & 0.58 & 0.7761 & $3.92 \times 10^{-17}$ & $2.00 \times 10^{-14}(509.26)$ & $1.73 \times 10^{-14}(442.08)$ \\
\hline CLD9_25_09_2c & 1422.20 & 1.01 & 1.3842 & $7.00 \times 10^{-17}$ & $2.32 \times 10^{-14}(331.90)$ & $1.47 \times 10^{-14}(210.51)$ \\
\hline CLD9_28_09_1a & 1434.11 & 0.28 & 0.0098 & $5.35 \times 10^{-19}$ & $9.05 \times 10^{-15}(16911.79)$ & $1.37 \times 10^{-15}(2555.99)$ \\
\hline CLD9_28_09_1b & 1434.13 & 0.32 & 0.0093 & $5.08 \times 10^{-19}$ & $5.19 \times 10^{-15}(10223.71)$ & $1.05 \times 10^{-15}(2064.01)$ \\
\hline CLD9_28_09_1c & 1434.16 & 0.43 & 0.0124 & $6.76 \times 10^{-19}$ & $6.35 \times 10^{-15}(9391.70)$ & $2.66 \times 10^{-16}(393.23)$ \\
\hline CLD9_28_09_1d & 1434.19 & 0.63 & 0.0174 & $9.49 \times 10^{-19}$ & $4.92 \times 10^{-15}(5184.55)$ & $1.44 \times 10^{-15}(1519.16)$ \\
\hline CLD9_28_09_2a & 1435.04 & 0.10 & 0.0081 & $4.40 \times 10^{-19}$ & $1.17 \times 10^{-15}(2664.48)$ & $7.30 \times 10^{-16}(1657.98)$ \\
\hline CLD9_28_09_2b & 1435.06 & 0.92 & 0.0176 & $9.60 \times 10^{-19}$ & $4.21 \times 10^{-15}(4390.07)$ & $1.00 \times 10^{-15}(1045.57)$ \\
\hline CLD9_28_09_2c & 1435.09 & 0.71 & 0.0077 & $4.19 \times 10^{-19}$ & $2.02 \times 10^{-15}(4814.28)$ & $1.40 \times 10^{-16}(333.88)$ \\
\hline
\end{tabular}

shown wall loss rates for sulphuric acid of $1.7 \times 10^{-3} \mathrm{~s}^{-1}$, corresponding to a lifetime of approximately $10 \mathrm{~min}$. Assuming ammonia to behave in a similar way to sulphuric acid in the CLOUD chamber, this suggests that the transport between the walls and the gas phase is orders of magnitude too slow to maintain a constant gas phase ammonia mixing ratio during the cloud formation.

A further possible source of ammonia is the un-activated particles. Once the cloud forms, the ammonia vapour pressure over these deliquesced aerosol will be higher than over the droplets, and ammonia may be transferred via the gas phase from the aerosol to the droplets. However, from the data shown in Table 5, it can be seen that the ammonia contained in the particles was only $2-4$ times greater than the additional ammonia required for the droplets to reach their equilibrium value. Using CLD8_20_11_1b as an example again, the maximum ammonium loss from a non-activated aerosol can be calculated, such that the ammonia vapour pressure over that aerosol reaches the vapour pressure over a droplet. In this case, only approximately $16 \%$ of the ammonia can be removed from a non-activated aerosol, making it necessary that as little as $30 \%$ of the aerosol activate if the remaining aerosol were to supply the missing ammonia to the droplets. The aerosol in CLD8_20_11_1b had an $\mathrm{NH}_{4}^{+}: \mathrm{SO}_{4}^{2-}$ ratio of 1.67. As shown in Fig. 7, the vapour pressure over the aerosol is highly sensitive to the $\mathrm{NH}_{4}^{+}: \mathrm{SO}_{4}^{2-}$ ratio, particularly as this approaches 2 . This means that in other experiments where the $\mathrm{NH}_{4}^{+}: \mathrm{SO}_{4}^{2-}$ ratio was higher, an even smaller fraction of the ammonia in the unactivated aerosol can be given up. As shown in Fig. 6, 


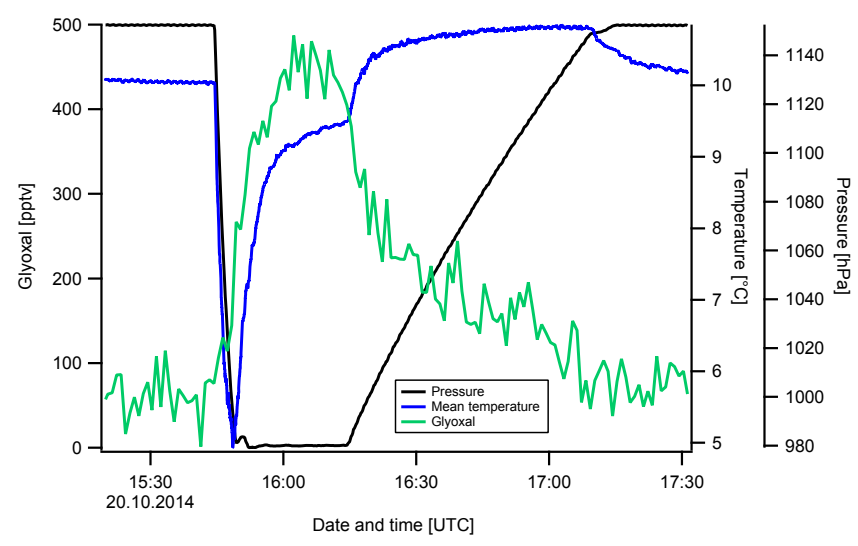

Figure 9. The change in glyoxal mixing ratio during an expansion performed in the CLOUD chamber as part of a series of isoprene oxidation experiments. Pressure and temperature are also shown, for reference.

the model likely overestimates the activation, particularly at larger aerosol numbers, however in order to provide enough ammonia, only a minority of the aerosol could have been activated. A visual inspection of the aerosol diameters measured with the SMPS showed that in all experiments, the majority of the aerosol grew during the cloud periods, and must therefore have activated to form cloud droplets. To summarise, the unactivated aerosol likely released some ammonia during the cloud periods, however this would not have been sufficient to supply the missing ammonia to the cloud droplets.

\subsubsection{Glyoxal as an indicator of exchange between chamber walls and the gas phase}

During the analysis of other experiments being carried out in the CLOUD chamber (ozone initiated oxidation of isoprene), high precision measurements of gas phase gyoxal were performed. During these measurements, it was found that as soon as the pressure decrease associated with an expansion began, the gas phase glyoxal increased rapidly from around 50 pptv to almost 500 pptv (Fig. 9). Glyoxal is relatively soluble, with an effective Henrys law coefficient of approximately $4 \times 10^{5} \mathrm{M} \mathrm{atm}^{-1}$ at $298 \mathrm{~K}$ in pure water (Ip et al., 2009), a value that increases by orders of magnitude for solutions containing sulphate (Ip et al., 2009; Kampf et al., 2013). Therefore this gas phase increase occurs in spite of the simultaneous uptake by the droplets. Ammonia is comparably soluble, with the effective Henry's law coefficient ranging between approximately $1 \times 10^{4} \mathrm{M} \mathrm{atm}^{-1}$ for a solution $\mathrm{pH}$ of 7 , and $1 \times 10^{7} \mathrm{M} \mathrm{atm}^{-1}$ when the $\mathrm{pH}$ is 4 (Seinfeld and Pandis, 2006). It is possible that the pressure change and increased turbulence during the decompression of the chamber lead to a better ventilation of the chamber walls. This would be characterised by a higher eddy diffusion coefficient, increasing the rate of exchange between the gas phase and the walls above the value that is observed during non-decompression periods.

Although high-precision ammonia measurements are not available for the CLOUD8 and CLOUD9 experiments, we expect any soluble gas adsorbed onto the chamber walls to respond to the pressure change in a similar way as glyoxal has been shown to behave. In the experiments with neutral or semi-neutral seed aerosol, a large amount of ammonia was injected into the chamber, which was partly taken up by the initially acidic seed, and partly deposited on the chamber walls. A re-mobilisation of ammonia from the chamber walls similar to that observed for glyoxal would lead to a large amount of ammonia in the gas phase, which could be taken up by the droplets.

In summary, it is not possible to support the assumption of a constant gas phase ammonia mixing ratio. It is likely that the droplets take up a large amount of ammonia from the gas phase, due to a rapid mobilisation of ammonia that was previously deposited on the chamber walls. However, it is not possible to quantify the size of this source. It is also likely that a certain amount of ammonia is transferred from the unactivated aerosol to the cloud droplets during the cloud formation.

As mentioned above, the amount of gas phase ammonia is very small when the $\mathrm{NH}_{4}^{+}: \mathrm{SO}_{4}^{2-}$ ratio is low (below approximately 1.0 ). Below, we show that the more acidic experiments are uninfluenced by the uncertainty in gas phase ammonia, as for these experiments it was only present at trace levels. We believe it is still interesting to include the more neutralised experiments in the analysis to investigate the sensitivity of the results to ammonium in the droplets and aerosol. In order to perform the model simulations, we maintain the assumption of a constant gas phase, as a base case, and discuss the implications further below.

\subsection{Aerosol growth and the effect of ammonia}

In this section, the modelled and measured growth of the dry aerosol volume before and after the expansion is discussed.

The $\mathrm{pH}$ of droplets formed during the expansions was seldom above 5, due to the uptake of $\mathrm{SO}_{2}$ and rapid production of $\mathrm{SO}_{4}^{2-}$ at higher $\mathrm{pH}$, and the resulting reduction in $\mathrm{pH}$. The only exceptions were experiments such as CLD8_05_12_1a and CLD8_05_12_1b where there were comparatively high gas phase $\mathrm{NH}_{3}$ mixing ratios (approximately 21 and $24 \mathrm{pptv}$ respectively, determined with the E-AIM model, as described in Sect. 3). A total of 12 of the experiments were performed at $\mathrm{NH}_{4}^{+}: \mathrm{SO}_{4}^{2-}$ ratios of greater than 1 .

The modelled and measured change in total volume of the aerosol population was calculated by integrating the dry aerosol size distribution (as measured by the SMPS attached to the total sampling line), and subtracting the total volume before the cloud period from that afterwards. Both modelled and measured data were corrected for particle losses during the expansion, by multiplying the volume after the expan- 

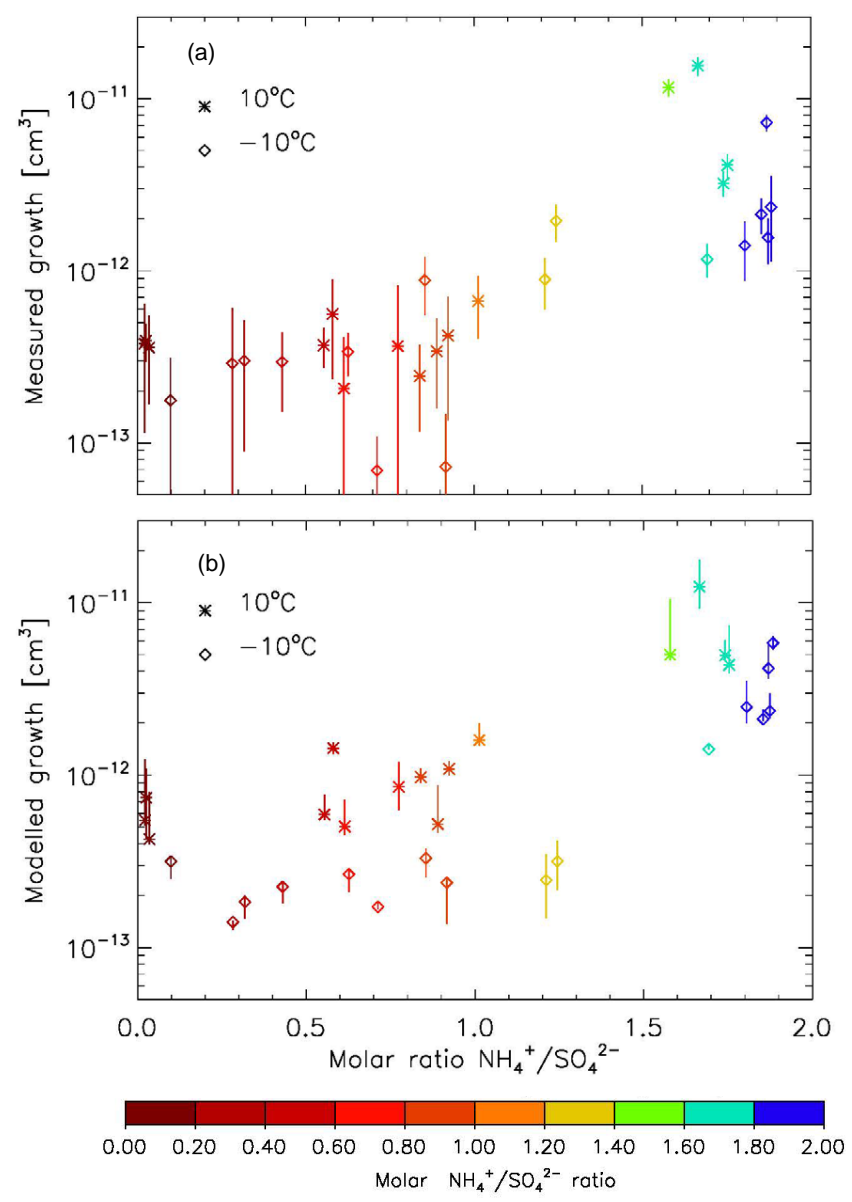

Figure 10. (a) The measured growth in the total aerosol volume as a function of $\mathrm{NH}_{4}^{+} / \mathrm{SO}_{4}^{2-}$ ratio in the seed aerosol, at 10 and $-10{ }^{\circ} \mathrm{C}$. The growth is determined as the difference in aerosol volume before and after the cloud. The error bars on the measured growth stem from the uncertainty in diameter in the SMPS measurements (which translates to approximately $14 \%$ in volume for particles with a diameter greater than $50 \mathrm{~nm}$ and $22 \%$ for those with a diameter less than $50 \mathrm{~nm}$ ). (b) As in (a), except here the modelled data are presented. The error bars stem from simulations carried out using the high and low limits of the dew point, as determined from the SIMONE data.

sion by the ratio of the number density of aerosol before the expansion to that after the expansion.

The dependence of the aerosol growth on the seed aerosol composition is shown in Fig. 10a and b, for the measured and modelled growth respectively. The aerosol growth during the supersaturated periods clearly depends on the aerosol seed composition, with the strength of the effect increasing rapidly at $\mathrm{NH}_{4}^{+}: \mathrm{SO}_{4}^{2-}$ ratios above approximately 1 . This is due to the fact that the more neutral seeds are in equilibrium with a higher gas phase $\mathrm{NH}_{3}$ amount, which will partition into the cloud droplets when they form. This leads to a higher $\mathrm{pH}$ during the cloud phase and accelerated $\mathrm{SO}_{2}$ oxidation. For the aerosols with an $\mathrm{NH}_{4}^{+}: \mathrm{SO}_{4}^{2-}$ ratio above 1.2 , the additional amount of ammonium which would partition to the droplets under the constant gas phase assumption would have more than balanced the sulphate in the droplets, leading to a very large increase in $\mathrm{pH}$, and correspondingly, a very large increase in aerosol growth. In contrast, at $\mathrm{NH}_{4}^{+}: \mathrm{SO}_{4}^{2-}$ ratios below approximately 1 , there is little ammonia in the gas phase, and it does not influence the aerosol growth. The modelled dependence of aerosol growth on seed composition is very similar to the measured dependence, however Fig. 10b shows that the model systematically predicts greater aerosol growth at $10^{\circ} \mathrm{C}$ than at $-10^{\circ} \mathrm{C}$, an effect that is not seen in the measured data (in the experimental data it appears that the lower reaction rates at lower temperatures are balanced by the greater solubility of the gases). This may point to a slightly too large temperature dependence of the reaction rate constants, and indeed, using the temperature dependence of Maahs (1983) leads to a slight closing of the gap between the $-10^{\circ} \mathrm{C}$ and the $10^{\circ} \mathrm{C}$ modelled points (not shown). However, as the rate constants given in the studies of Erickson et al. (1977) and Maahs (1983) were based on measurements at $25^{\circ} \mathrm{C}$, weakening the temperature dependence also increases the modelled growth of aerosol at $10^{\circ} \mathrm{C}$. During the CLOUD8 experiments at $-10^{\circ} \mathrm{C}$, the presence of an ice phase was detected from the PPD-2K measurements. The onset of ice formation was also seen in the change of SIMONE forward scattering and depolarisation signals. This ice formation was always detected after the pressure decrease had ended, by which time the aerosol growth had also ceased. No further growth of the aerosol was observed during or after the formation of ice. An upgrade in the chamber expansion system between CLOUD8 and CLOUD9 prevented formation of ice during the CLOUD9 experiments.

A comparison of the modelled and measured aerosol volume growth is shown in Fig. 11a. Here, the gas phase ammonia mixing ratio was calculated with E-AIM, as described above, and was held constant during the cloud period. In general, the modelled volume growth matches the measured values to within a factor of two (dot dashed lines in Fig. 11). This indicates that observed aerosol growth in the CLOUD chamber matches the growth predicted by the reaction rate constants specified by Hoffmann (1986), at both 10 and $-10^{\circ} \mathrm{C}$. The model appears to slightly overestimate the aerosol growth at $10^{\circ} \mathrm{C}$, in the case of the more acidic seed aerosols, while the $-10^{\circ} \mathrm{C}$ points are more evenly distributed about the 1:1 line. Applying the temperature dependence of Maahs (1983) has the effect of increasing the modelled growth of both the -10 and the $10^{\circ} \mathrm{C}$ points (the latter to a slightly lesser degree), and rather decreases the agreement between the modelled and measured values (not shown).

It should once again be noted that the assumption of a constant gas phase ammonia cannot be supported. While the walls almost certainly provide a large source of ammonia, this source cannot be quantified and the relatively good agreement of modelled and measured growth during the 12 partially to fully neutralised experiments must be ascribed 

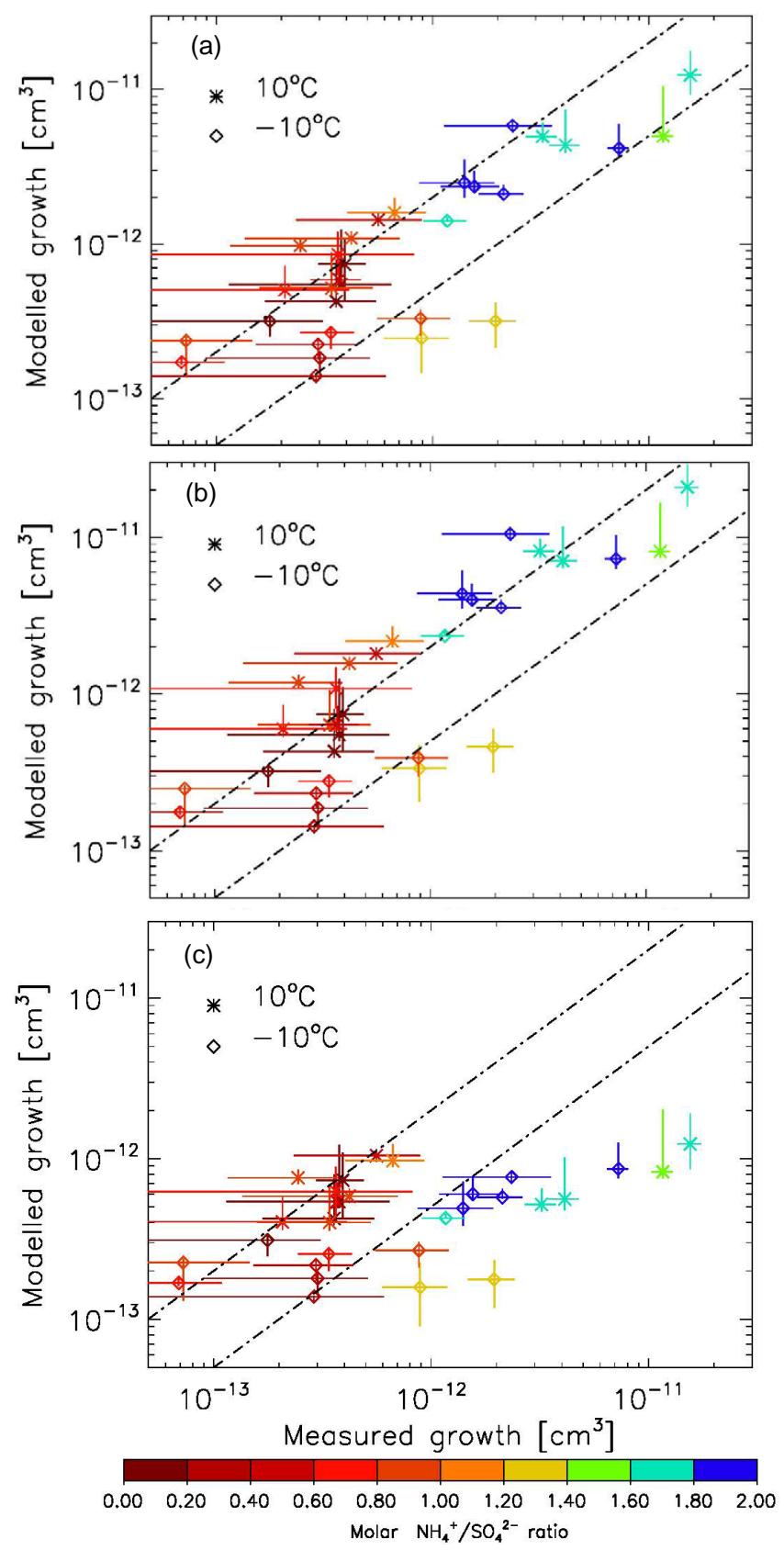

Figure 11. (a) The modelled vs. observed total increase in aerosol volume due to the aqueous phase oxidation of $\mathrm{SO}_{2}$ to $\mathrm{SO}_{4}^{2-}$ at 10 and $-10^{\circ} \mathrm{C}$. Note that the masses are corrected to account for any particle loss during the expansion (see text). The dashed lines indicate the range of a factor of two higher or lower than the observed values. The error bars are as for Fig. 10. (b) As for (a), but with doubled gas phase $\mathrm{NH}_{3}$. (c) As for (a), but with no gas phase $\mathrm{NH}_{3}$.

to coincidence in each case. As the modelled results of the more neutralised experiments depend on the gas phase $\mathrm{NH}_{3}$ mixing ratio, two further model runs were performed, the first with doubled gas phase $\mathrm{NH}_{3}$ (Fig. 11b), the second with no gas phase $\mathrm{NH}_{3}$ (Fig. 11c), to assess the sensitivity. From panel c, it is clear that the gas phase $\mathrm{NH}_{3}$ is necessary for the model to reproduce the observed growth of the more neutralised seed aerosol. Particularly in the $10^{\circ} \mathrm{C}$ experiments at $\mathrm{NH}_{4}^{+}: \mathrm{SO}_{4}^{2-}$ ratios of close to 2 , the modelled aerosol growth is far too low if gas phase $\mathrm{NH}_{3}$ is neglected. On the other hand, doubling the gas phase $\mathrm{NH}_{3}$ with respect to the original values determined with E-AIM leads to an overestimation of the aerosol growth. In general however, it can be seen that although the modelled growth is clearly influenced by the gas phase $\mathrm{NH}_{3}$, small variations do not greatly impact aerosol growth. It is also clear that for the more acidic aerosol, the results are essentially identical if one assumes no gas phase ammonia, or a constant gas phase ammonia mixing ratio in equilibrium with the aerosol, as the latter is almost negligible.

\subsection{Influence of ions on aqueous phase oxidation of $\mathrm{SO}_{2}$}

One of the features of the CLOUD chamber is the ability to perform experiments under conditions with varying concentrations of gas phase ions. By applying a $30 \mathrm{kV}$ electric field across the chamber, ions can effectively be swept from the chamber, providing a neutral environment. In the absence of the clearing field, natural radiation sources such as galactic cosmic rays (GCR) lead to the ionisation of gases, creating ion pair concentrations of approximately $650 \mathrm{~cm}^{-3}$, representative of the number concentrations found in the atmospheric boundary layer. Higher ion-pair concentrations can be achieved by using a pion beam from the CERN proton synchrotron, however for the time period in which the experiments described here were conducted, this was not available. Instead, the CIGAR (Corona Ion Generator for Aerosol Research) was used to create higher ion concentrations. The CIGAR is a stainless steel wire, $100 \mathrm{~mm}$ in length and $100 \mu \mathrm{m}$ in diameter, situated in an argon surrounding atmosphere in direct contact with the air in the CLOUD chamber. A voltage of $3.5 \mathrm{kV}$ is applied across the wire, which is just below the voltage necessary to produce a corona discharge. The CIGAR produced ion pair concentrations of approximately $1.5 \times 10^{5}$ to $2.0 \times 10^{5} \mathrm{~cm}^{-3}$.

$\mathrm{SO}_{2}$ mixing ratios of $20 \mathrm{ppbv}$ correspond to approximately $5 \times 10^{11}$ molecules $\mathrm{cm}^{-3}$, at $1013.25 \mathrm{hPa}$ and as the aqueous phase oxidation proceeds rapidly, one would not necessarily expect an influence of, at most, a few hundred thousand ions $\mathrm{cm}^{-3}$ on the aerosol growth. Nevertheless, a few experiments were performed to confirm that this was the case, and that no unexpected surface charge effects could influence the results. The modelled and measured aerosol growth are again plotted in Fig. 12, with the colours indicating under which conditions the experiments were performed. All except five of the experiments were performed under natural GCR conditions, however the CIGAR and neutral points show no sign of any systematic bias, confirming that ions do not have a measurable influence on $\mathrm{SO}_{2}$ uptake and oxidation. 


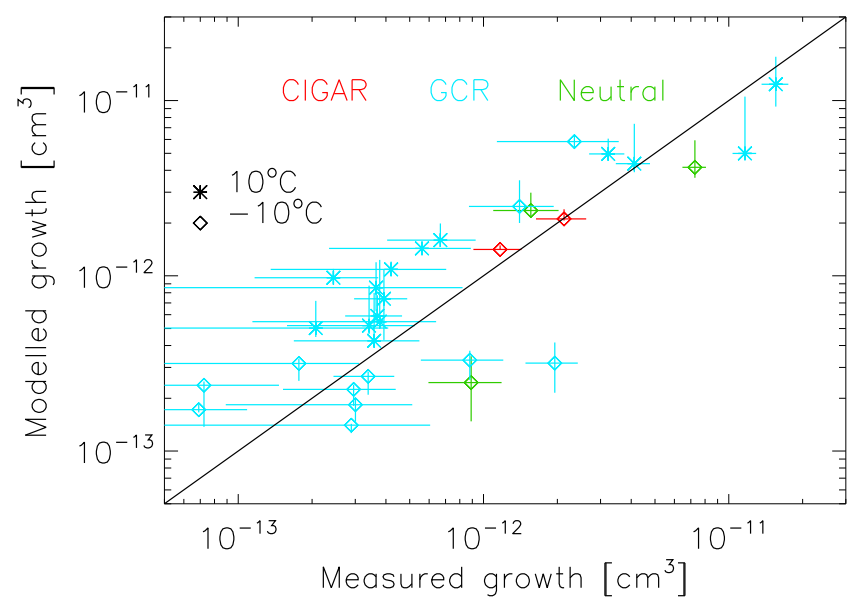

Figure 12. As for Fig. 11a, except that the colours indicate the ion conditions under which the experiments were performed: ion free (neutral), natural ion concentrations (GCR) and enhanced ion concentrations (CIGAR).

\section{Conclusions}

Experiments have been performed to investigate the aqueous phase oxidation of $\mathrm{SO}_{2}$ by $\mathrm{O}_{3}$ in cloud droplets. The observed aerosol growth was compared with the growth predicted by a model using the reaction rate constants recommended by Hoffmann (1986), which are widely used in the modelling of these reactions. It was shown that the modelled growth under acidic seed aerosol conditions generally agrees with the observed growth, suggesting that the rate constants of Hoffmann (1986), which were measured in bulk solutions, do indeed accurately represent the chemistry occurring in dispersed aqueous systems. This contrasts with the findings of at least two previous studies (Hoppel et al., 1994b; Caffrey et al., 2001), and seems to confirm the suggestion made by those authors that the observed disagreement resulted from the presence of contaminants such as ammonia. Furthermore, we have performed what we believe to be the first laboratory-based measurements of the aqueous phase oxidation of $\mathrm{SO}_{2}$ in a population of super-cooled cloud droplets, and confirmed that the generally accepted temperature dependence of the oxidation reactions, measured by Erickson et al. (1977), is consistent with our experimental results at temperatures of $-10^{\circ} \mathrm{C}$.

Experiments were also performed for partially to essentially fully neutralised aerosol (ammonium sulphate), however as there is likely to be a large, unquantifiable source of ammonia from the chamber walls during the cloud formation, these experiments can only be used to illustrate the sensitivity of modelled aerosol growth to ammonia.

The agreement between the model and the experimental data presented here illustrates that chamber experiments, performed under well defined conditions, may be used to determine aqueous phase reaction rate constants. Additionally, such experiments may be used to determine reaction rate constants in super-cooled droplets, which are important for atmospheric applications but impossible to measure in bulk solutions.

Acknowledgements. We thank Martin Schnaiter for his assistance with the SIMONE and PPD-2K data interpretation. The PPD-2K was made available by funding from the Deutsche Forschungsgemeinschaft under grant SCHN 1140/2-1. C. R. Hoyle was supported by the Swiss National Science Foundation (SNSF) (grant number 200021_140663). T. B. Kristensen gratefully acknowledges funding from the German Federal Ministry of Education and Research (BMBF) through the CLOUD12 project. J. Craven received funding through the Dreyfus Award EP-11-117. N. M. Donahue received funding through US National Science Foundation Grants AGS-1447056 and AGS-1439551. This research has received funding from the EC Seventh Framework Programme (Marie Curie Initial Training Network "CLOUD-TRAIN" grant no. 316662, and the German Federal Ministry of Education and Research (project no. 01LK1222A and B).

Edited by: V.-M. Kerminen

\section{References}

Barth, M. C., Rasch, P. J., Kiehl, J. T., Benkovitz, C. M., and Schwartz, S. E.: Sulfur chemistry in the National Center for Atmospheric Research Community Climate Model: description, evaluation, features, and sensitivity to aqueous chemistry, J. Geophys. Res., 105, 1387-1415, doi:10.1029/1999JD900773, 2000.

Caffrey, P., Hoppel, W., Frick, G., Pasternack, L., Fitzgerald, J., Hegg, D., Gao, S., Leaitch, R., Shantz, N., Albrechcinski, T., and Ambrusko, J.: In-cloud oxidation of $\mathrm{SO}_{2}$ by $\mathrm{O}_{3}$ and $\mathrm{H}_{2} \mathrm{O}_{2}$ : cloud chamber measurements and modeling of particle growth, J. Geophys. Res., 106, 27587-27601, doi:10.1029/2000JD900844, 2001.

Clegg, S., Brimblecombe, P., and Wexler, A.: Thermodynamic model of the system $\mathrm{H}^{+}-\mathrm{NH}_{4}^{+}-\mathrm{SO}_{4}^{2}-\mathrm{NO}_{3}-\mathrm{H}_{2} \mathrm{O}$ at tropospheric temperatures, J. Phys. Chem.-US, 102, 2137-2154 doi:10.1021/jp973042r, 1998.

Coburn, S., Ortega, I., Thalman, R., Blomquist, B., Fairall, C. W., and Volkamer, R.: Measurements of diurnal variations and eddy covariance (EC) fluxes of glyoxal in the tropical marine boundary layer: description of the Fast LED-CE-DOAS instrument, Atmos. Meas. Tech., 7, 3579-3595, doi:10.5194/amt-7-3579-2014, 2014.

DeCarlo, P. F., Kimmel, J. R., Trimborn, A., Northway, M. J., Jayne, J. T., Aiken, A. C., Gonin, M., Fuhrer, K., Horvath, T., Docherty, K. S., Worsnop, D. R., and Jimenez, J. L.: Fielddeployable, high-resolution, time-of-flight aerosol mass spectrometer, Anal. Chem., 78, 8281-8289, doi:10.1021/ac061249n, 2006.

Duplissy, J., Merikanto, J., Franchin, A., Tsagkogeorgas, G., Kangasluoma, J., Wimmer, D., Vuollekoski, H., Schobesberger, S., Lehtipalo, K., Flagan, R., Brus, D., Donahue, N., Vehkämäki, H., Almeida, J., Amorim, A., Barmet, P., Bianchi, F., Breitenlechner, M., Dunne, E., Guida, R., Henschel, H., Junninen, H., 
Kirkby, J., Kürten, A., Kupc, A., Määttänen, A., Makhmutov, V., Mathot, S., Nieminen, T., Onnela, A., Praplan, A., Riccobono, F., Rondo, L., Steiner, G., Tome, A., Walther, H., Baltensperger, U., Carslaw, K., Dommen, J., Hansel, A., Petäjä, T., Sipilä, M., Stratmann, F., Vrtala, A., Wagner, P., Worsnop, D., Curtius, J., and Kulmala, M.: Effect of ions on sulfuric acid-water binary particle formation II: Experimental data and comparison with QCnormalized classical nucleation theory, J. Geophys. Res.-Atmos., 121, doi:10.1002/2015JD023539, 2016.

Dutcher, C. S., Wexler, A. S., and Clegg, S. L.: Surface tensions of inorganic multicomponent aqueous electrolyte solutions and melts, J. Phys. Chem.-US, 114, 12216-12230, doi:10.1021/jp105191z, 2010.

Erickson, R., Yates, L., Clark, R., and Mcewen, D.: Reaction of sulfur-dioxide with ozone in water and its possible atmospheric significance, Atmos. Environ., 11, 813-817, doi:10.1016/00046981(77)90043-9, 1977.

Fahey, D. W., Gao, R.-S., Möhler, O., Saathoff, H., Schiller, C., Ebert, V., Krämer, M., Peter, T., Amarouche, N., Avallone, L. M., Bauer, R., Bozóki, Z., Christensen, L. E., Davis, S. M., Durry, G., Dyroff, C., Herman, R. L., Hunsmann, S., Khaykin, S. M., Mackrodt, P., Meyer, J., Smith, J. B., Spelten, N., Troy, R. F., Vömel, H., Wagner, S., and Wienhold, F. G.: The AquaVIT-1 intercomparison of atmospheric water vapor measurement techniques, Atmos. Meas. Tech., 7, 3177-3213, doi:10.5194/amt-7-3177-2014, 2014.

Faloona, I.: Sulfur processing in the marine atmospheric boundary layer: a review and critical assessment of modeling uncertainties, Atmos. Environ., 43, 2841-2854, doi:10.1016/j.atmosenv.2009.02.043, 2009.

Forster, P., Ramaswamy, V., Artaxo, P., Berntsen, T., Betts, R., Fahey, D., Haywood, J., Lean, J., Lowe, D., Myhre, G., Nganga, J., Prinn, R., Raga, G., Schulz, M., and Van Dorland, R.: Climate Change 2007: The Physical Science Basis. Contribution of Working Group I to the Fourth Assessment Report of the Intergovernmental Panel on Climate Change, chap. 2, Changes in Atmospheric Constituents and in Radiative Forcing, Cambridge University Press, Cambridge, UK and New York, NY, USA, 2007.

Fuchs, N. A. and Sutugin, A. G.: High dispersed aerosols, in: Topics in Current Aerosol Research, edited by: Hidy, G. M. and Brock, J. R., Pergamon, New York, USA, 1-60, 1971.

Glen, A. and Brooks, S. D.: A new method for measuring optical scattering properties of atmospherically relevant dusts using the Cloud and Aerosol Spectrometer with Polarization (CASPOL), Atmos. Chem. Phys., 13, 1345-1356, doi:10.5194/acp-13-13452013, 2013.

Goff, J. A. and Gratch, S.: Low-pressure properties of water from -160 to $212^{\circ} \mathrm{F}$, T. Am. Soc. Heat. Vent. Eng., 52, 95-121, 1946.

Graus, M., Mueller, M., and Hansel, A.: High resolution PTR-TOF: quantification and formula confirmation of VOC in real time, J. Am. Soc. Mass Spectr., 21, 1037-1044, doi:10.1016/j.jasms.2010.02.006, 2010.

Hobbs, P. V.: Simultaneous airborne measurements of cloud condensation nuclei and sodium-containing particles over the ocean, Q. J. Roy. Meteor. Soc., 97, 263-271, doi:10.1002/qj.49709741302, 1971.
Hoffmann, M.: On the kinetics and mechanism of oxidation of aquated sulfur-dioxide by ozone, Atmos. Environ., 20, 11451154, doi:10.1016/0004-6981(86)90147-2, 1986.

Hoppel, W., Frick, G., Fitzgerald, J., and Larson, R.: Marine boundary-layer measurements of new particle formation and the effects nonprecipitating clouds have on aerosol-size distribution, J. Geophys. Res., 99, 14443-14459, doi:10.1029/94JD00797, 1994a.

Hoppel, W., Frick, G., Fitzgerald, J., and Wattle, B.: A cloud chamber study of the effect that nonprecipitating water clouds have on the aerosol-size distribution, Aerosol Sci. Tech., 20, 1-30, doi:10.1080/02786829408959660, 1994b.

Ip, H. S. S., Huang, X. H. H., and Yu, J. Z.: Effective Henry's law constants of glyoxal, glyoxylic acid, and glycolic acid, Geophys. Res. Lett., 36, L01802, doi:10.1029/2008GL036212, 2009.

Kampf, C. J., Waxman, E. M., Slowik, J. G., Dommen, J., Pfaffenberger, L., Praplan, A. P., Prevot, A. S. H., Baltensperger, U., Hoffmann, T., and Volkamer, R.: Effective Henry's law partitioning and the salting constant of Glyoxal in Aerosols Containing Sulfate, Environ. Sci. Technol., 47, 4236-4244, doi:10.1021/es400083d, 2013.

Kirkby, J., Curtius, J., Almeida, J., Dunne, E., Duplissy, J., Ehrhart, S., Franchin, A., Gagne, S., Ickes, L., Kuerten, A., Kupc, A., Metzger, A., Riccobono, F., Rondo, L., Schobesberger, S., Tsagkogeorgas, G., Wimmer, D., Amorim, A., Bianchi, F., Breitenlechner, M., David, A., Dommen, J., Downard, A., Ehn, M., Flagan, R. C., Haider, S., Hansel, A., Hauser, D., Jud, W., Junninen, H., Kreissl, F., Kvashin, A., Laaksonen, A., Lehtipalo, K., Lima, J., Lovejoy, E. R., Makhmutov, V., Mathot, S., Mikkila, J., Minginette, P., Mogo, S., Nieminen, T., Onnela, A., Pereira, P., Petaja, T., Schnitzhofer, R., Seinfeld, J. H., Sipila, M., Stozhkov, Y., Stratmann, F., Tome, A., Vanhanen, J., Viisanen, Y., Vrtala, A., Wagner, P. E., Walther, H., Weingartner, E., Wex, H., Winkler, P. M. Carslaw, K. S., Worsnop, D. R., Baltensperger, U., and Kulmala, M.: Role of sulphuric acid, ammonia and galactic cosmic rays in atmospheric aerosol nucleation, Nature, 476, 429-433, doi:10.1038/nature10343, 2011.

Kosak-Channing, L. and Helz, G.: Solubility of ozone in aqueoussolutions of $0-0.6 \mathrm{M}$ ionic-strength at $5-30^{\circ} \mathrm{C}$, Environ. Sci. Technol., 17, 145-149, doi:10.1021/es00109a005, 1983.

Kreidenweis, S., Walcek, C., Feingold, G., Gong, W., Jacobson, M., Kim, C., Liu, X., Penner, J., Nenes, A., and Seinfeld, J.: Modification of aerosol mass and size distribution due to aqueous-phase $\mathrm{SO}_{2}$ oxidation in clouds: Comparisons of several models, J. Geophys. Res., 108, 4213, doi:10.1029/2002JD002697, 2003.

Kulmala, M.: How particles nucleate and grow, Science, 302, 1000 1001, doi:10.1126/science.1090848, 2003.

Lowe, P. R. and Ficke, J. M.: The Computation of Saturation Vapor Pressure, Tech. Rep., Environmental Prediction Research Facility (Navy), Monterey, CA, USA, 1974.

Maahs, H.: Kinetics and mechanism of the oxidation of S(IV) by ozone in aqueous-solution with particular reference to $\mathrm{SO}_{2}$ conversion in nonurban tropospheric clouds, J. Geophys. Res., 88, 721-732, doi:10.1029/JC088iC15p10721, 1983.

McMurry, P. H. and Grosjean, D.: Gas and aerosol wall losses in Teflon film smog chambers, Environ. Sci. Technol., 19, 11761182, doi:10.1021/es00142a006, 1985. 
Miller, D., Gertler, A., Whitbeck, M., and Lamb, D.: Ozone-induced oxidation of $\mathrm{SO}_{2}$ in simulated clouds, J. Geophys. Res., 91, 14439-14444, doi:10.1029/JD091iD13p14439, 1986.

Müller, B. and Heal, M.: The mass accommodation coefficient of ozone on an aqueous surface, Phys. Chem. Chem. Phys., 4, 3365-3369, doi:10.1039/b202491h, 2002.

Pandis, S. and Seinfeld, J.: Sensitivity analysis of a chemical mechanism for aqueous-phase atmospheric chemistry, J. Geophys. Res., 94, 1105-1126, doi:10.1029/JD094iD01p01105, 1989.

Poling, B. E., Prausnitz, J. M., and O'Connell, J. P.: The Properties of Gases and Liquids, McGraw-Hill, New York, 2001.

Riccobono, F., Schobesberger, S., Scott, C. E., Dommen, J., Ortega, I. K., Rondo, L., Almeida, J., Amorim, A., Bianchi, F., Breitenlechner, M., David, A., Downard, A., Dunne, E. M., Duplissy, J., Ehrhart, S., Flagan, R. C., Franchin, A., Hansel, A., Junninen, H., Kajos, M., Keskinen, H., Kupc, A., Kuerten, A., Kvashin, A. N., Laaksonen, A., Lehtipalo, K., Makhmutov, V., Mathot, S., Nieminen, T., Onnela, A., Petaja, T., Praplan, A. P., Santos, F. D., Schallhart, S., Seinfeld, J. H., Sipila, M., Spracklen, D. V., Stozhkov, Y., Stratmann, F., Tome, A., Tsagkogeorgas, G., Vaattovaara, P., Viisanen, Y., Vrtala, A., Wagner, P. E., Weingartner, E., Wex, H., Wimmer, D., Carslaw, K. S., Curtius, J., Donahue, N. M., Kirkby, J., Kulmala, M., Worsnop, D. R., and Baltensperger, U.: Oxidation products of biogenic emissions contribute to nucleation of atmospheric particles, Science, 344, 717-721, doi:10.1126/science.1243527, 2014.

Rodhe, H.: Human impact on the atmospheric sulfur balance, Tellus A, 51, 110-122, 1999.

Schnaiter, M., Büttner, S., Möhler, O., Skrotzki, J., Vragel, M., and Wagner, R.: Influence of particle size and shape on the backscattering linear depolarisation ratio of small ice crystals - cloud chamber measurements in the context of contrail and cirrus microphysics, Atmos. Chem. Phys., 12, 10465-10484, doi:10.5194/acp-12-10465-2012, 2012.

Schwartz, S. E.: Mass transport considerations pertinent to aqueous phase reactions of gases in liquid water clouds, in: Chemistry of Multiphase Atmospheric Systems, edited by: Jaeschke, W., NATO ASI series Series G: Ecological Sciences, 6, 415-471, Springer-Verlag Berlin Heidelberg New York Tokyo, 1986.

Schwartz, S.: Mass-transport limitation to the rate of in-cloud oxidation of $\mathrm{SO}_{2}$ - re-examination in the light of new data, Atmos. Environ., 22, 2491-2499, doi:10.1016/0004-6981(88)90480-5, 1988.
Seinfeld, J. H. and Pandis, S. N.: Atmospheric Chemistry and Physics, From Air Pollution to Climate Change, Wiley, New York, USA, 2006.

Smith, R. M. and Martell, A. E.: Critical Stability Constants, vol. 4: Inorganic Complexes, Plenum, New York, 1976.

Steele, R., Gertler, A., Katz, U., Lamb, D., and Miller, D.: Cloud chamber studies of dark transformations of sulfur-dioxide in cloud droplets, Atmos. Environ., 15, 2341-2352, 1981.

Thalman, R. and Volkamer, R.: Inherent calibration of a blue LED-CE-DOAS instrument to measure iodine oxide, glyoxal, methyl glyoxal, nitrogen dioxide, water vapour and aerosol extinction in open cavity mode, Atmos. Meas. Tech., 3, 1797-1814, doi:10.5194/amt-3-1797-2010, 2010.

Thalman, R., Baeza-Romero, M. T., Ball, S. M., Borrás, E., Daniels, M. J. S., Goodall, I. C. A., Henry, S. B., Karl, T., Keutsch, F. N., Kim, S., Mak, J., Monks, P. S., Muñoz, A., Orlando, J., Peppe, S., Rickard, A. R., Ródenas, M., Sánchez, P., Seco, R., Su, L., Tyndall, G., Vázquez, M., Vera, T., Waxman, E., and Volkamer, R.: Instrument intercomparison of glyoxal, methyl glyoxal and $\mathrm{NO}_{2}$ under simulated atmospheric conditions, Atmos. Meas. Tech., 8, 1835-1862, doi:10.5194/amt-8-1835-2015, 2015.

Vochezer, P., Järvinen, E., Wagner, R., Kupiszewski, P., Leisner, T., and Schnaiter, M.: In situ characterization of mixed phase clouds using the Small Ice Detector and the Particle Phase Discriminator, Atmos. Meas. Tech., 9, 159-177, doi:10.5194/amt-9-1592016, 2016.

Volkamer, R., Baidar, S., Campos, T. L., Coburn, S., DiGangi, J. P., Dix, B., Eloranta, E. W., Koenig, T. K., Morley, B., Ortega, I., Pierce, B. R., Reeves, M., Sinreich, R., Wang, S., Zondlo, M. A., and Romashkin, P. A.: Aircraft measurements of BrO, IO, glyoxal, $\mathrm{NO}_{2}, \mathrm{H}_{2} \mathrm{O}, \mathrm{O}_{2}-\mathrm{O}_{2}$ and aerosol extinction profiles in the tropics: comparison with aircraft-/ship-based in situ and lidar measurements, Atmos. Meas. Tech., 8, 2121-2148, doi:10.5194/amt-8-2121-2015, 2015.

Wexler, A. and Clegg, S.: Atmospheric aerosol models for systems including the ions $\mathrm{H}^{+}, \mathrm{NH}_{4}^{+}, \mathrm{Na}^{+}, \mathrm{SO}_{4}^{2-}, \mathrm{NO}_{3}^{-}, \mathrm{Cl}^{-}, \mathrm{Br}^{-}$, and $\mathrm{H}_{2} \mathrm{O}$, J. Geophys. Res., 107, 4207, doi:10.1029/2001JD000451, 2002.

Zaveri, R. A., Easter, R. C., Fast, J. D., and Peters, L. K.: Model for Simulating Aerosol Interactions and Chemistry (MOSAIC), J. Geophys. Res., 113, D13204, doi:10.1029/2007JD008782,2008. 